\title{
Identification and ecotoxicity of degradation products of chloroacetamide herbicides from UV-treatment of water
}

\author{
Souissi, Yasmine; Bouchonnet, Stéphane; Bourcier, Sophie; Kusk, Kresten Ole; Sablier, Michel; \\ Andersen, Henrik Rasmus
}

\section{Published in:}

Science of the Total Environment

Link to article, DOI:

10.1016/j.scitotenv.2013.04.064

Publication date:

2013

Link back to DTU Orbit

Citation (APA):

Souissi, Y., Bouchonnet, S., Bourcier, S., Kusk, K. O., Sablier, M., \& Andersen, H. R. (2013). Identification and ecotoxicity of degradation products of chloroacetamide herbicides from UV-treatment of water. Science of the Total Environment, 458, 527-534. https://doi.org/10.1016/j.scitotenv.2013.04.064

\section{General rights}

Copyright and moral rights for the publications made accessible in the public portal are retained by the authors and/or other copyright owners and it is a condition of accessing publications that users recognise and abide by the legal requirements associated with these rights.

- Users may download and print one copy of any publication from the public portal for the purpose of private study or research.

- You may not further distribute the material or use it for any profit-making activity or commercial gain

- You may freely distribute the URL identifying the publication in the public portal 
This is a post print of the article published in the journal "Science of The Total Environment. 2013. 458-460C. pp 527-534". The publishers version is available at the permanent link: http://dx.doi.org/10.1016/j.scitotenv.2013.04.064.

\title{
Identification and ecotoxicity of degradation products of \\ chloroacetamide herbicides from $U V$ - treatment of water
}

\section{Yasmine Souissi ${ }^{a}$, Stéphane Bouchonnet ${ }^{a}$, Sophie Bourcier ${ }^{a}$, Kresten Ole Kusk ${ }^{b}$, Michel Sablier ${ }^{a}$, Henrik Rasmus Andersen ${ }^{b^{*}}$}

\footnotetext{
${ }^{a}$ Ecole Polytechnique, Laboratoire des Mécanismes Réactionnels, CNRS, route de Saclay, 91128 Palaiseau cedex, France.

${ }^{b}$ Department of Environmental Engineering, Technical University of Denmark, Miljoevej 113, 2800 Kgs. Lyngby, Denmark.

*Corresponding author: henrik@ndersen.net.
}

\begin{abstract}
The widespread occurrence of chlorinated herbicides and their degradation products in the aquatic environment raises health and environmental concerns. As a consequence pesticides, and to a lesser degree their degradation products, are monitored by authorities both in surface waters and drinking waters. In this study the formation of degradation products from ultraviolet (UV) treatment of the three chloroacetamide herbicides acetochlor, alachlor and metolachlor and their biological effects were investigated. UV treatment is mainly used for disinfection in water and wastewater treatments. First, the chemical structures of the main UVdegradation products were identified using GC-MS and LC-MS. The main transformation reactions were dechlorination, mono- and multi-hydroxylation and cyclizations.

The ecotoxicity of the mixed photoproducts formed by UV-treatment until $90 \%$ of the original pesticide was converted was compared to the toxicity of chloroacetamides using the green alga Pseudokirchneriella subcapitata, the crustacean Daphnia magna and the marine bacteria Vibrio fischeri as test organisms. UV-treatment of alachlor and metolachlor increased the toxicity compared to the parent compounds while an equal toxicity was found for photolysis products of acetochlor. This suggests that toxic photodegradation products are generated from chloroacetamides under UV-treatment. An important perspective of this finding is that the photolysis products are at least as toxic as the parent compounds.
\end{abstract}

Keywords Chloroacetamide, photolysis, mass spectrometry, toxicity, photoproducts. 


\section{Introduction}

Chloroacetamides are among the most widely used herbicides. They are used to control annual grasses and broadleaf weeds in corn, soybean, sorghum, cotton and several other crops. Their mode-of-action is to inhibit the early development of susceptible weeds by preventing biosynthesis of very long fatty acid chains thus affecting cell integrity (Böger et al., 2000; Matthes and Boger, 2002).

Among the most commonly used chloroacetamides are acetochlor (2-Chloro- $\mathrm{N}$ (ethoxymethyl)-N-(2-ethyl-6-methylphenyl)acetamide), alachlor (2-Chloro- $\mathrm{N}-(2,6-$ diethylphenyl)-N-(methoxymethyl)acetamide) and metolachlor ( 2-Chloro-N-(2-ethyl-6-methylphenyl)-N-(1-methoxypropan-2-yl)acetamide) (Li et al., 2010). The U.S. Environmental Protection Agency reported their annual use in the USA at 9.1 to 13.6 million kilograms for Acetochlor, 2.7 to 4.1 million kilograms for Alachlor and 6.8 to 9.1 million kilograms for Metolachlor (Kiely et al., 2002). Because of their widespread use and récalcitrant nature, herbicide residues are frequently detected in ground and surface waters (Gascuel-Odoux et al., 2009; Lewis et al., 2009). Chloroacetamides are listed in the Drinking Water Contaminant Candidate List of the US Environmental Protection Agency (USEPA, 2009) and are among the most frequently detected agricultural herbicides by the National Water Quality Assessment (NAWQA) of the U.S. Geological Survey (Barbash et al., 2001). The frequencies of detection in ground water samples at all concentrations were $0.2,2.2$ and $11.7 \%$ for acetochlor, alachlor and metolachlor respectively (Cavalier et al., 1991; Barbash et al., 2001; Rocha et al., 2008). Considerable concentrations of chloroacetamides, varying according to the matrices from 0.1 to $10 \mu \mathrm{g} / \mathrm{L}$, have been detected in surface water and ground water (Cavalier et al., 1991; Barbash et al., 2001; Konstantinou et al., 2006; Rocha et al., 2008). Chloroacetamides have also been detected in drinking water (Coupe and Blomquist, 2004). Hence, numerous studies have focused on control and optimization of pesticide removal from ground and surface water sources (Reichenberger et al., 2007) during drinking water treatment.

In recent years, several reviews of the occurrence and fate of transformation by-products of manmade chemicals have been made (Richardson et al.,, 2003; Richardson et al., 2007; Wei et al., 2010; Bull et al., 2011). Degradation products are generated during water treatment processes including oxidation. A particular emphasis has been focused on pharmaceuticals with several reviews and studies dedicated to their degradation products in the environment (FattaKassinos et al., 2011a; Fatta-Kassinos et al., 2011b; Horvat et al., 2012) and in water treatment systems e.g. water works (Ternes et al., 2002; Kosjek and Heath, 2008; Kosjek et al., 2009). In these artificial systems biodegradation occurs concurrently with engineered processes like oxidation reactions with chlorine, chlorine dioxide, ozone and transformations by UV (Kosjek and Heath, 2008; Hollender et al., 2009; Kosjek et al., 2009).

In a recent review dealing with emerging contaminants from pesticide degradation, it was highlighted that degradation products were generated from transformation processes such as hydrolysis, biodegradation and chemical oxidation (Richardson, 2008). Pesticide degradation is governed by environmental factors which should theoretically attenuate their concentration in soil and water. However, unknown and potentially toxic compounds are generated. Furthermore these transformation products have been reported to be present at greater concentrations than the parent herbicides (Richardson, 2008). These transformation products were also described as exhibiting an equivalent or even greater level of toxicity than the parent 
pesticides (Hladik et al., 2005a). Hladik et al. (Hladik et al., 2005b) also reported that in some environmental water samples (Chesapeake Bay) the total concentration of non-ionic degradation products of chloroacetamide herbicide were about 20 to 30 times higher than the concentration of parent chloroacetamide herbicides. According to Boxall and Sinclair, 2001, out of 89 pesticide degradation products, 70 percent were equally or less toxic than their parent compounds and 30 percent exhibited a greater toxicity. In total Hladik and co-authors identified 26 chloroacetamide degradation products in drinking water sources (Hladik et al., 2008). Although abundant information on the health risks of chloroacetamide herbicides is available, much less is known about the effects of their degradation products (Hladik et al., 2005b). This has prompted environmental authorities to include some degradation products in investigations regarding herbicide fate and transportation in aquatic ecosystems (EU, 1998; USEPA, 2009).

In this context the purpose of the present study was to identify by chemical analysis the degradation products produced by UV-treatment of Acetochlor, Alachlor and Metolachlor in aqueous solution and to describe the ecotoxicological effect of these degradation products. Direct photolysis by high pressure UV-lamp was used to degrade the herbicides as water treatment utilities are increasingly employing UV-treatment as an alternative disinfection method replacing chlorination (Cabaj et al., 1996; Hijnen et al., 2006). Since UV is employed to disinfect and not specifically degrade compounds it can only be expected that a minor fraction of a given pesticide will be degraded considering the large difference in UV dosage used for disinfection compared to targeted photolysis (Hijnen et al., 2006; Hansen and Andersen, 2012). In order to investigate which degradation products are formed following UV treatment of chloroacetamide herbicides and to determine potential toxicity the chosen herbicides were exposed to a UV dosage degrading $90 \%$ of the parent compound. With this methodology we expected to create a mixture of products similar to those formed by UV disinfection, while further UV-treatment would increasingly form products from continued photolysis of the primary photolysis products. Afterward, chemical analysis was performed to identify the formed photolysis products in the resulting solution. For that purpose, liquid chromatography coupled to quadrupole/time-of-flight mass spectrometer (LC-Q/TOF-MS) and gas chromatography coupled to an ion trap mass spectrometer (GC-ITMS) were utilised. These two analytical techniques were chosen for their complimentary ability to detect polar and apolar compounds. An analytical strategy for the identification of degradation products was also developed. This analytical strategy has been developed and applied to allow reliable identification of numerous degradation products. Our strategy combined three complementary major steps for generating data that could be used to identify the degradation products: collision induced dissociation for fragmentation mechanism establishment, high resolution measurements for elemental composition determination and use of isotope labelled molecules for structural confirmation (Bourcier et al., 2010; Bouchonnet et al., 2011; Bouchonnet et al., 2012; Souissi et al., 2012; Coffinet et al., 2012). The labelled molecules allow the location of structural modifications induced by UV irradiation through the comparison of data with those of unlabelled molecules (Coffinet et al,. 2012).

Following degradation product identification, ecotoxicity of these three chloracetamides was compared with mixtures of photo-transformation products formed by their respective UVirradiation. Ecotoxicity assessment of photolyzed and non-photolyzed spiked water samples were carried out using three standardized short-term bioassays with the crustacean, Daphnia 
magna, the algae, Pseudokirchneriella subcapitata, and the bioluminescent bacteria, Vibrio fischeri.

\section{Materials and methods}

\subsection{Chemicals and standards}

Acetochlor, Alachlor, Metolachlor and deuterated analogues: Acetochlor- $d_{11}$ (99\% atom D),

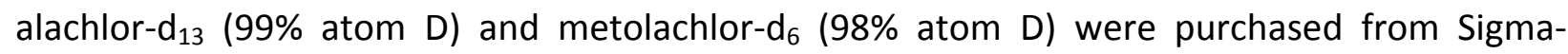
Aldrich (St. Quentin Fallavier - France). Chromatographic-grade solvents - methanol, acetonitrile and methylene chloride - were also purchased from Sigma-Aldrich and used as received (99\% purity).

\subsubsection{Photolysis experiments}

A photoreactor equipped with a high-pressure mercury lamp (HPL-N 125W/542 E27 SG, Philips, 94856 Ivry-sur-Seine, France) was constructed for the photolysis experiments. The lamp is intended for water treatment and emits light in a broad spectra ranging from 200 to $1100 \mathrm{~nm}$. Six quartz cylindrical containers were placed on a circular trajectory around the lamp. During the radiation the solutions were stirred with a sonicator (Bioblock Scientific 91631, Illkirch, France). This setup allowed irradiation of several solutions simultaneously. The lamp was placed into the inner part of the reactor cooled by water circulation at $25 \pm 2{ }^{\circ} \mathrm{C}$ to avoid uncontrolled heating of the irradiated solution. The quartz containers were filled with $30 \mathrm{~mL}$ of stock solutions and irradiated. The reactor was covered by aluminium foil to optimize solution irradiation, and avoid light emission outside the reactor. For toxicity experiments a solution of $100 \mathrm{mg} \cdot \mathrm{L}^{-1}$ of each herbicide was prepared in Milli-Q water (Milli-Q, Millipore, France). Subsamples of this stock solution were irradiated with UV for $90 \mathrm{~min}$ corresponding to degradation of approximately $90 \%$ of each of the herbicides with concurrent formation of photoproducts. For each treatment experiment a "dark control" solution was also prepared. The dark controls consisted of parent herbicides for which all the experimental steps were performed except for the UV-irradiation. The dark control solution and $90 \mathrm{~min}$ irradiated solutions were diluted in the appropriate test media for the ecotoxicity assays to attain the final test concentration series.

\subsubsection{Solid phase extraction}

Solid-phase extractions were carried out prior to chemical analysis of the dark control and photolyzed solutions. Each reaction sample was extracted using a SPE cartridge (Atoll column $30 \mathrm{ATH}, 200 \mathrm{mg}$ resin in $3 \mathrm{~mL}$ cartridge, Interchim, Montluçon, France). The cartridge was conditioned with $3 \mathrm{~mL}$ of methanol followed by $3 \mathrm{~mL}$ of distilled water. $4 \mathrm{~mL}$ of a 5:95 methanol:water mixture was used for washing the SPE cartridge. After elution of $10 \mathrm{~mL}$ of sample at a rate of approximately 60 drops per min, the cartridge was vacuum-dried and eluted with $8 \mathrm{~mL}$ of methanol and $4 \mathrm{~mL}$ of acetonitrile with $0.1 \%$ formic acid, successively. The extracts were concentrated at ambient temperature under a gentle stream of nitrogen until dryness. The dried samples were then re-diluted the corresponding mobile phase according to the analytical technique and transferred into a glass vial. For the in injection in GC-MS, it was re- 
diluted in $100 \mu \mathrm{l}$ of methylene chloride. For LC/MS analysis, the mobile phase was $200 \mu \mathrm{L}$ of $\mathrm{H}_{2} \mathrm{O} / \mathrm{CH}_{3} \mathrm{CN} 0.1 \%$ FA (60/40).

The selected elution solvent for SPE extraction and mobile phases for LC/MS and GC/MS, analysis were determined based on comparison of many common solvents. The selection was based achieving the highest number of peaks detected in each method and the largest area of chromatographic peaks.

2.2. Chemical analysis of the herbicides and their transformation products using chromatography coupled with mass spectrometry

Degradation products with low polarity were analyzed by gas chromatography coupled with mass spectrometry (GC-MS) using a "CP3800" gas chromatograph system equipped with a "CP8400" autosampler and coupled with a "Saturn 2000" ion trap mass spectrometer (Varian, Les Ulis - France). The chromatographic separation was performed on a $60 \mathrm{~m}$ "Factor four VF10-MS" (10\% phenyl, 90\% methylpolysiloxane) capillary column (internal diameter: $0.25 \mathrm{~mm}$, film thickness: $0.25 \mu \mathrm{m}$ ) from Varian. The chromatographic separation and mass spectrometric analysis were performed as described by (Bouchonnet et al., 2011).

Liquid chromatography/quadrupole time-of-flight mass spectrometry (LC/Q-TOF MS/MS) (2690 liquid chromatography module from Waters, Q-Tof Premier, Waters) was used for the identification of polar degradation products. Reverse phase chromatographic separations were performed using a "Pursuit XRs Ultra" column $2.8 \mu \mathrm{m}$ C18 50 × $2.0 \mathrm{~mm}$ from Varian. Chromatographic and spectrometric conditions were adopted as in our previous work (Bourcier et al., 2010).

Further details on the chromatographic methods and mass spectroscopy conditions applied for both LC and GC analysis are given in Supporting Information and by Coffinet et al., 2012.

Table 1. Experimental conditions for algae, daphnia and bacteria standard ecotoxicity tests performed on chloracetamides and the mixtures of photolysis products.

\begin{tabular}{|c|c|c|c|}
\hline & \multicolumn{3}{|c|}{ Test } \\
\hline & Algae & Crustacean cladoceran & Bacteria \\
\hline Species & Pseudokirchneriella subcapitata & Daphnia magna & Vibrio fischeri \\
\hline Temperature $\left({ }^{\circ} \mathrm{C}\right)$ & 20 & 20 & 15 \\
\hline Optimal $p H$ & $7.8 \pm 0.2$ & $8.0 \pm 0.3$ & $7.0 \pm 0.2$ \\
\hline Light source & Light intensity of 10,000 lux & Darkness & - \\
\hline Media volume & $4 \mathrm{ml} / \mathrm{vial}$ & $25 \mathrm{ml} /$ beaker & $200 \mu \mathrm{l} / \mathrm{vial}$ \\
\hline Organisms stocked & $5-10 \cdot 10^{3}$ cells $/ \mathrm{ml}$ at start & 5 animals/beaker & - \\
\hline Aeration & $\begin{array}{c}\text { No aeration } \\
\text { (air exchange via a hole in the lid } \\
\text { of the growth vial) }\end{array}$ & $\begin{array}{c}\text { No aeration } \\
\text { (beakers are covered by a watch } \\
\text { glass) }\end{array}$ & - \\
\hline Test duration & $72 \mathrm{~h}$ & $48 \mathrm{~h}$ & $30 \mathrm{~min}$ \\
\hline Replicates & 3 with 5 control replicates & 4 & 2 \\
\hline Assessment endpoint & Biomass growth rate inhibition & Daphnia immobilization & Bioluminescence inhibition \\
\hline Measurement endpoint & Chlorophyll fluorescence & immobile daphnia & luminescence \\
\hline $\begin{array}{l}\text { International Standard } \\
\text { Organisation Reference }\end{array}$ & $\begin{array}{l}\text { ISO 8692, } 2004 \\
\text { (ISO8692, 2004) }\end{array}$ & $\begin{array}{l}\text { ISO 6341, 1996 } \\
\text { (ISO6341, 1996) }\end{array}$ & $\begin{array}{l}\text { ISO 11348-3, } 1998 \\
\text { (ISO11348-3, 1998) }\end{array}$ \\
\hline
\end{tabular}




\subsection{Ecotoxicity evaluation}

The toxicity of the chloroacetamides and photolysis products solutions of the chloroacetamide, produced by UV treatment, was evaluated with three standardized ecotoxicity assays (ISO6341, 1996; ISO8692, 2004; ISO11348-3, 1998). A summary of experimental conditions for the algal, daphnia and bacterial methods is given in Table 1. The daphnia and algal experiments were conducted under the same temperature and lighting conditions as the culture conditions. Full details of the experimental conditions of the ecotoxicity experiments are presented in the Supplementary Information.

\section{Results and discussion}

\subsection{Identification of the photo-degradation products}

For each herbicide, the initial concentration was reduced by approximately $90 \%$ by UV irradiation in order to produce a mixture of photo degradation products. To achieve structural characterization of the photo degradation products experiments were performed with a combination of GC-MS ${ }^{n}$ (gas chromatography followed by multiple stage mass spectrometry) and LC-HR/MS-MS (liquid chromatography followed by high resolution tandem mass spectrometry). The first stage in the strategy of photo degradation product identification was to compare chromatograms of irradiated solutions with those of reference solutions.

In GC/MS chromatograms (as shown in figure S4), the degradation products peaks were visually distinguishable. In LC/MS chromatograms, the presence of degradation products was suspected through the appearance of a new chromatographic profile in the photolyzed solution compared to the reference solution of each chloracetamide. Thus, the extraction of the ions and their ion daughter from the total ion flow (Figure S5) was done simultaneously in both solutions as a confirmation of the fact that those compound are newly generated DPs.

As some products might not be directly visible in the chromatogram a long investigation of the chromatograms that carefully compares the chromatograms of irradiated with non irradiated solution were performed. Thirty one degradation products were detected for the three herbicides. Products that occurred at very low concentrations (relative abundance of peaks less than 1\%) were not investigated further. The relative abundance and suggested structures of the photo degradation products are presented in Table 2. The methodology for characterization of degradation products is fully described in previous published studies (Bourcier et al., 2010; Bouchonnet et al., 2011; Bouchonnet et al., 2012; Souissi et al., 2012; Coffinet et al., 2012) in which we described how establishment of characteristic dissociation pathways of molecular ions permitted systematic structure elucidation of degradation products. The detailed structure elucidation of the photoproducts of metolachlor is described in Coffinet et al,. 2012 and the similar identification of the same products of alachlor and acetochlor is supported in the the data and the mechanistic interpretations of the mass spectras are supported by the data shown in supporting information namely figures S6, S7 and S8 as well as tables S2 and S3. 
Table 2. Molecular weight, structure and relative abundance for each chloracetamide (P1 for Acetochlor , P2 for alachlor , P3 for metolachlor ) and the suggested structure of those photoproducts that occurred with $>1 \%$ relative abundance in $\mathrm{LC}$ or $\mathrm{GC}$ chromatograms from samples created by UV-treatment of each chloracetamide. $\left(\mathrm{R}\right.$ or $\mathrm{R}^{\prime}=\mathrm{CH}_{3}$ for $\mathrm{Alachlor}$, $\mathrm{H}$ for $\mathrm{Acetochlor}$ and Metolachlor, $\mathrm{X}=\mathrm{OCH}_{3}$ for Alachlor, $\mathrm{OCH}_{2} \mathrm{CH}_{3}$ for Acetochlor and $\mathrm{CH}_{2} \mathrm{OCH}_{3}$ for Metolachlor, $\mathrm{X}^{\prime}=\mathrm{H}$ for Alachlor and Acetochlor and $\mathrm{CH}_{3}$ for Metolachlor).

\begin{tabular}{|c|c|c|c|c|c|c|c|c|c|c|c|c|c|c|}
\hline & Compound & MW & Structures & $\mathrm{RA}^{\mathrm{a}}(\%)$ & & Compound & $\mathrm{MW}$ & Structures & $\mathrm{RA}^{\mathrm{a}}$ & & Compound & $\mathrm{MW}$ & Structures & $\mathrm{RA}^{\mathrm{a}}(\%)$ \\
\hline$P_{1}$ & Acetochlor & 269 & & - & $\mathrm{P}_{2}$ & Alachlor & 269 & & - & $\mathrm{P}_{3}$ & Metolachlor & 283 & & - \\
\hline A & $\begin{array}{l}\text { Alachlor } \\
\text { Acetochlor } \\
\text { Metolachlor }\end{array}$ & $\begin{array}{l}251 \\
251 \\
265\end{array}$ & & $\begin{array}{l}26 \\
7 \\
8\end{array}$ & B & $\begin{array}{l}\text { Alachlor } \\
\text { Acetochlor } \\
\text { Metolachlor }\end{array}$ & $\begin{array}{l}235 \\
235 \\
-\end{array}$ & & $\begin{array}{l}8 \\
4 \\
-\end{array}$ & C & $\begin{array}{l}\text { Alachlor } \\
\text { Acetochlor } \\
\text { Metolachlor }\end{array}$ & $\begin{array}{l}191 \\
177 \\
-\end{array}$ & & $\begin{array}{l}2 \\
3 \\
-\end{array}$ \\
\hline$D^{b}$ & $\begin{array}{l}\text { Alachlor } \\
\text { Acetochlor } \\
\text { Metolachlor }\end{array}$ & $\begin{array}{l}233 \\
233 \\
247\end{array}$ & & $\begin{array}{l}14 \\
16+11 \\
1+2\end{array}$ & $E^{b}$ & $\begin{array}{l}\text { Alachlor } \\
\text { Acetochlor } \\
\text { Metolachlor }\end{array}$ & $\begin{array}{l}189 \\
175 \\
-\end{array}$ & & $\begin{array}{l}5 \\
3+3 \\
-\end{array}$ & $\mathrm{F}$ & $\begin{array}{l}\text { Alachlor } \\
\text { Acetochlor } \\
\text { Metolachlor }\end{array}$ & $\begin{array}{l}189 \\
175 \\
-\end{array}$ & & $\begin{array}{l}3 \\
4 \\
-\end{array}$ \\
\hline$G^{c}$ & $\begin{array}{l}\text { Alachlor } \\
\text { Acetochlor } \\
\text { Metolachlor }\end{array}$ & $\begin{array}{l}- \\
- \\
265\end{array}$ & $\uparrow_{(5)}^{(6)}$ & $\begin{array}{l}- \\
- \\
33+23+ \\
8+4+2\end{array}$ & $\mathrm{H}$ & $\begin{array}{l}\text { Alachlor } \\
\text { Acetochlor } \\
\text { Metolachlor }\end{array}$ & $\begin{array}{l}- \\
- \\
263\end{array}$ & & $\begin{array}{l}- \\
- \\
2\end{array}$ & I & $\begin{array}{l}\text { Alachlor } \\
\text { Acetochlor } \\
\text { Metolachlor }\end{array}$ & $\begin{array}{l}251 \\
251 \\
297\end{array}$ & & $\begin{array}{l}10 \\
6 \\
1\end{array}$ \\
\hline J & $\begin{array}{l}\text { Alachlor } \\
\text { Acetochlor } \\
\text { Metolachlor }\end{array}$ & $\begin{array}{l}237 \\
223 \\
-\end{array}$ & & $\begin{array}{l}34 \\
10 \\
-\end{array}$ & K & $\begin{array}{l}\text { Alachlor } \\
\text { Acetochlor } \\
\text { Metolachlor }\end{array}$ & \begin{tabular}{l|}
- \\
251 \\
-
\end{tabular} & & $\begin{array}{l}- \\
28 \\
-\end{array}$ & $L^{d}$ & $\begin{array}{l}\text { Alachlor } \\
\text { Acetochlor } \\
\text { Metolachlor }\end{array}$ & $\begin{array}{l}- \\
269 \\
-\end{array}$ & & $\begin{array}{l}- \\
5 \\
-\end{array}$ \\
\hline
\end{tabular}

${ }^{a}$ Relative abundances for photoproducts were evaluated integrating peak areas on $\mathrm{MH}^{+}$ion currents in ESI-MS (LC-MS) and CI-MS (GC-MS), ${ }^{b}$ Two isomers are possible for Acetochlor and Metolachlor; $\mathrm{R}(\mathrm{H})$ and $\mathrm{R}^{\prime}\left(\mathrm{CH}_{3}\right)$ switch together, ${ }^{\mathrm{c}}$ Six isomers are possible: Hydroxylation can occur in the positions (1 to 6$)$, ${ }^{\mathrm{d}}$ Two isomers are possible: the second hydroxylation can take place in positions 1 and 2 . 
Moreover, we assumed that the generated photoproducts retained the parent skeleton and common moieties with the original structure. Thus the presence of characteristic ion fragments facilitated the structure assignments. Hydroxylations and cyclizations (ring formations) were the main observed reactions in our study. A general scheme suggesting the main photolysis reaction pathways based on the major observed degradation products are proposed in Figure 1. The main degradation product structures suggest that irradiation initially leads to the cleavage of the $\mathrm{C}-\mathrm{Cl}$ (carbon-chlorine) bond eliminating a $\mathrm{Cl}^{-}$-radical to form a radical of the dechlorinated chloroacetamide $[\mathbf{M}-\mathbf{C l}]$ : This radical leads to the formation of four families of compounds. The first one includes monohydroxylated compounds directly formed by the addition of a hydroxyl radical onto [M-Cl] resulting in photoproduct $\mathbf{A}$ (Figure 1; Table 2, second row) which was detected with both GC-MS and LC-MS for all three herbicides. The dechlorinated radical [M-Cl] formed from any of the chloroacetamides may also undergo cyclization before hydroxylation leading to the formation of I, obtained for all three pesticides, and $\mathbf{K}$ obtained only for Acetochlor. I loses an ethyl or a methyl radical for Alachlor and Acetochlor, respectively, to give J. From the bicyclic radical, an alternative reaction route was suggested involving the alpha cleavage of the alkyl substituent on the nitrogen atom leading to F (detected by GC-MS for Alachlor and Acetochlor). From [M-Cl]; another cyclization pathway implying one of the two alkyl chains of the aromatic ring to form D1 and D2 isomers is observed for the three pesticides. D1 and D2 can either eliminate the alkyl chain on the nitrogen atom to form E1 and E2 for Alachlor and Acetochlor or react with water to give the hydroxylated structure $\mathbf{H}$ for Metolachlor, $\mathbf{L} 1$ and $\mathbf{L} 2$ for Acetochlor. Finally, [M-Cl] can react with water to give $\mathbf{B}$ which was observed for Alachlor and Acetochlor. B loses the alkyl substituent on the nitrogen atom to provide $\mathbf{C}$ in the case of Alachlor and Acetochlor. A hydroxyl addition also occurs onto the aromatic ring (G1 to G3) and onto one of the alkyl chains (G4 to G6). Except for the compounds $\mathbf{G 1}$ to $\mathbf{G 6}$, all the hydroxylated degradation products are mainly observed in LCMS due to their polarity. (Figure 1; Table 2).

Photolysis products and pathways described in this work differ from those reported in our previous work concerning ozonation of the same chloroacetamides (Bouchonnet et al., 2012). In UV induced photolysis the chlorine atom is systematically eliminated whilst during ozonation it remains in the structures of all degradation products. Moreover, photolysis mainly induces hydroxylation processes, whereas ozonation mainly induces carboxylation of chloroacetamides. 

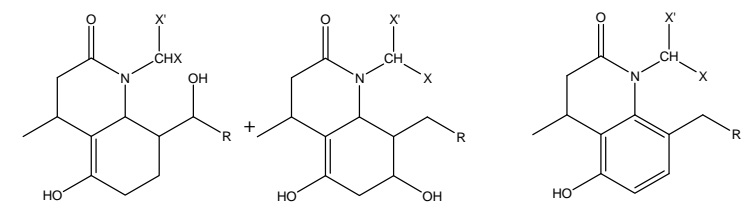

L1 $1_{\text {Ace }}$

$\mathbf{L} 2_{\text {Ace }}$<smiles>CC1CC1C</smiles>

$\mathbf{H}_{\text {Met }}$

$n v \bigcap_{\mathrm{H}_{2} \mathrm{O}}^{\mathrm{H}^{*}}$

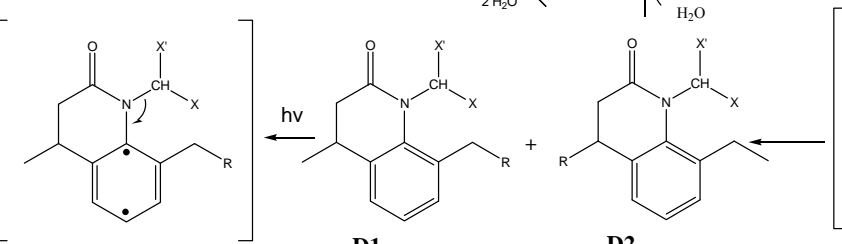

D1 $1_{\text {Ala, Ace, Met }}$

D2

$\operatorname{Mic}_{H \rightarrow}^{x}$

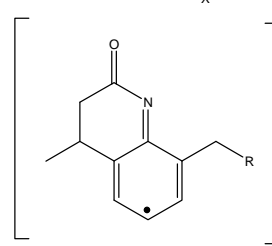

hv

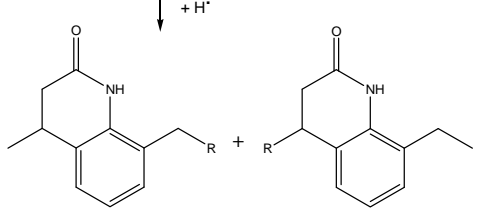

E1 $1_{\text {Ala, Ace }}$

E2

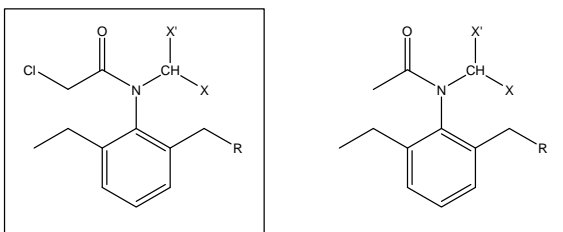

B $_{\text {Ala, Ace }}$

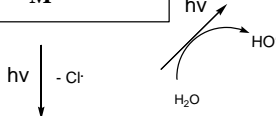

Ala, Ace

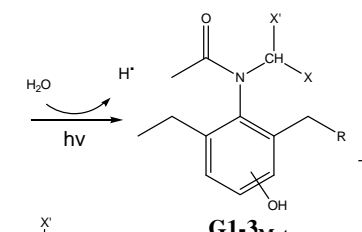

G1-3

$+\overbrace{\mathrm{OH}}$
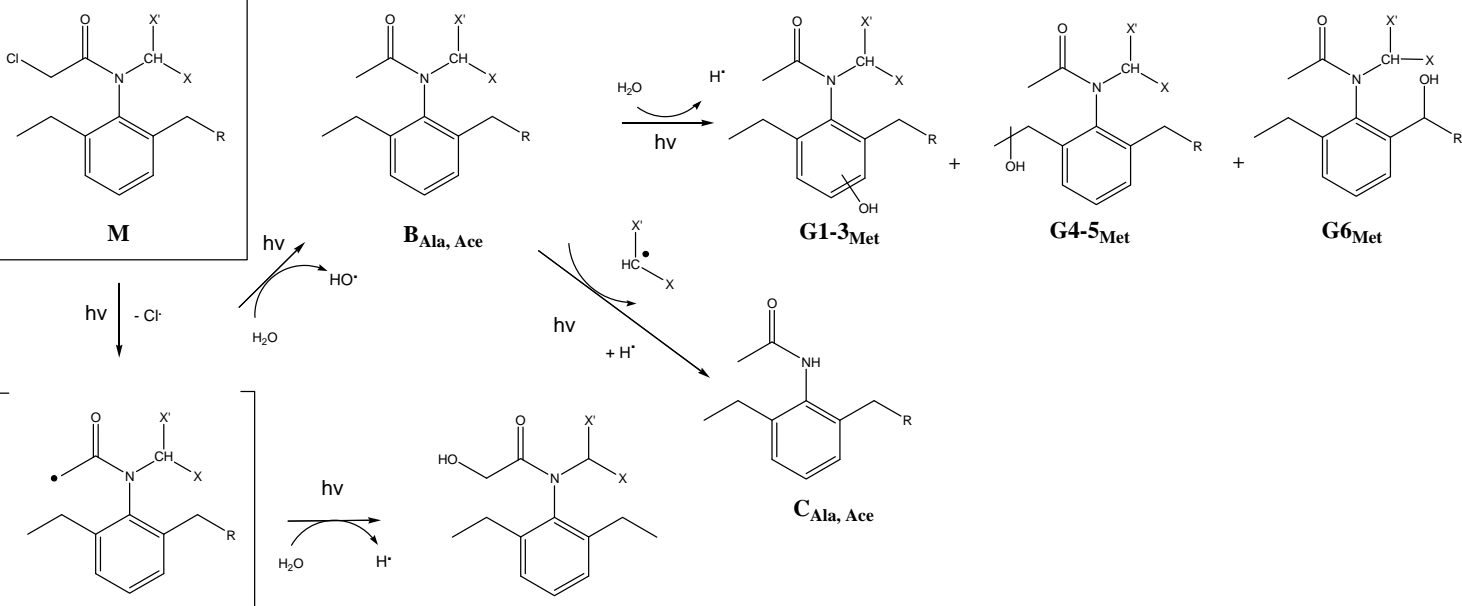

(1)

[M-Cl]

$\uparrow$

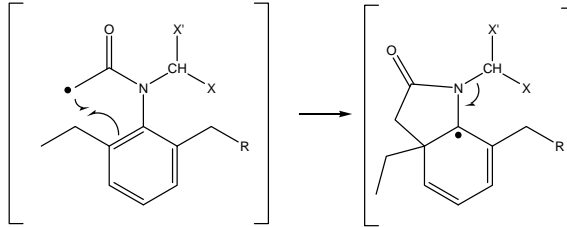

[M-Cl]

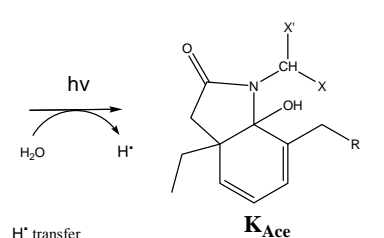

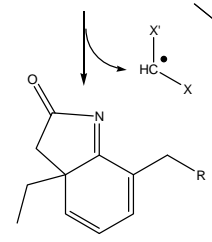

$F_{A}$

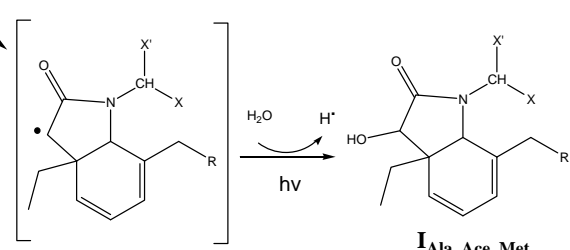

$I_{\text {Ala Ace, Met }}$

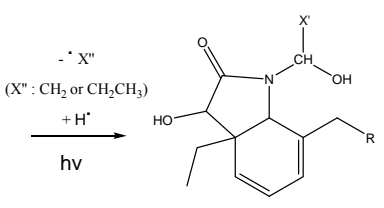

$\mathrm{J}_{\mathrm{Ala} \text {, Ace }}$

Figure 1. The suggested mechanism of chloracetamides (M) photodegradation . (R or $\mathrm{R}^{\prime}=\mathrm{CH}_{3}$ for Alachlor, $\mathrm{H}$ for Acetochlor and $\mathrm{Metolachlor}, \mathrm{X}=\mathrm{OCH} \mathrm{H}_{3}$ for $\mathrm{Alachlor}$, $\mathrm{OCH} \mathrm{CH}_{3}$ for $\mathrm{Acetochlor}$ and $\mathrm{CH}_{2} \mathrm{OCH}_{3}$ for Metolachlor, $\mathrm{X}^{\prime}=\mathrm{H}$ for Alachlor and Acetochlor and $\mathrm{CH}_{3}$ for Metolachlor). 


\subsection{Comparative toxicity of the three herbicides and their photo degradation products}

Toxicity assessment of photodegradation products formed by both solar radiation and UVtreatment is a major ecotoxicity and toxicity concern as generated intermediates could exhibit either loss of toxicity or greater toxicity than the parent compounds. Recent examples in the literature have indicated increased toxicity of photolysis products of extensively used herbicides and pesticides (Osano et al., 2002; Friedman et al., 2006; Bonnet et al., 2007; Mestankova et al., 2011; Virág et al., 2007).

Experimental median effective concentration $\left(\mathrm{EC}_{50}\right)$ values for the three selected standard ecotoxicity assays were obtained for solutions of Metolachlor, Alachlor and Acetochlor as well as for mixtures of their photolysis products obtained by UV treatment (until $90 \%$ of the parent chloroacetamides were degraded) and are presented in Table 2. The dose response curves behind each $\mathrm{EC}_{50}$ can be found in supporting information figures $\mathrm{S} 1, \mathrm{~S} 2$ and $\mathrm{S} 3$. Using the calculated values of $\mathrm{EC}_{50}$, a comparison can be made between the toxicity of the initial herbicides solution and the mixture of the herbicides photodegradation products. A lower $\mathrm{EC}_{50}$ indicates that less of a compound is needed to give the same toxic effect e.g. the formation of products more toxic than the parent compound.

Table 3. Measured fifty percent effective concentrations $\left(\mathrm{EC}_{50} \mathrm{~S}\right)$ of the investigated pesticides and their photolysis products with the three standard ecotoxicity assays

\begin{tabular}{|c|c|c|c|c|}
\hline Species & & & $E C_{50}{ }^{a}(\mu g / L)$ & 95\% Confidence Interval $(\mu \mathrm{g} / \mathrm{L})$ \\
\hline \multirow{6}{*}{$\begin{array}{c}\text { Pseudokirchneriella } \\
\text { subcapitata }\end{array}$} & \multirow{2}{*}{ Metolachlor } & Parent compound & 44.3 & $38.5-51.1$ \\
\hline & & Photolysed products & 25.6 & $21.8-30.0$ \\
\hline & \multirow{2}{*}{ Acetochlor } & Parent compound & 2.50 & $2.1-2.9$ \\
\hline & & Photolysed products & 2.12 & $1.76-2.55$ \\
\hline & \multirow{2}{*}{ Alachlor } & Parent compound & 6.69 & $4.21-10.6$ \\
\hline & & Photolysed products & 2.52 & $1.63-3.90$ \\
\hline \multirow{6}{*}{ Daphnia magna } & \multirow{2}{*}{ Metolachlor } & Parent compound & $22.3 \cdot 10^{3}$ & $(17.2-27.6) \cdot 10^{3}$ \\
\hline & & Photolysed products & $16.6 \cdot 10^{3}$ & $(12.6-20.7) \cdot 10^{3}$ \\
\hline & \multirow{2}{*}{ Acetochlor } & Parent compound & $6.29 \cdot 10^{3}$ & $(5.1-7.2) \cdot 10^{3}$ \\
\hline & & Photolysed products & $6.15 \cdot 10^{3}$ & $(5.0-7.0) \cdot 10^{3}$ \\
\hline & \multirow[t]{2}{*}{ Alachlor } & Parent compound & $7.50 \cdot 10^{3}$ & $(5.95-8.73) \cdot 10^{3}$ \\
\hline & & Photolysed products & $5.3610^{3}$ & $(3.60-6.84) \cdot 10^{3}$ \\
\hline \multirow{6}{*}{ Vibrio fischeri } & \multirow[t]{2}{*}{ Metolachlor } & Parent compound & $17.1 \cdot 10^{3}$ & $(15.3-19.1) \cdot 10^{3}$ \\
\hline & & Photolysed products & $7.33 \cdot 10^{3}$ & $(6.81-7.88) \cdot 10^{3}$ \\
\hline & \multirow[t]{2}{*}{ Acetochlor } & Parent compound & ${ }^{b}>200 \cdot 10^{3}$ & $>200 \cdot 10^{3}$ \\
\hline & & Photolysed products & $>200 \cdot 10^{3}$ & $>200 \cdot 10^{3}$ \\
\hline & \multirow[t]{2}{*}{ Alachlor } & Parent compound & $155 \cdot 10^{3}$ & $(142-171) \cdot 10^{3}$ \\
\hline & & Photolysed products & $96 \cdot 10^{3}$ & $(86-107) \cdot 10^{3}$ \\
\hline
\end{tabular}

${ }^{\mathrm{a}} \mathrm{EC}_{50}=$ the median effective concentration, which is the concentration causing a response in $50 \%$ of the test parameter

${ }^{\mathrm{b}}$ Higher than highest tested concentration).

The variability in species sensitivity for the three chloroacetamides was high with green algae ( $P$. subcapitata) being much more sensitive (lower $\mathrm{EC}_{50}$ ) than bioluminescent bacteria ( $V$. fischeri) or the crustacean (D. magna).

Previous studies on Metolachlor toxicity to $P$. subcapitata reported $\mathrm{EC}_{50}$ values ranging from 55 to $84 \mathrm{\mu g} / \mathrm{L}$ (Fairchild et al., 1997; Fairchild et al., 1998; Battaglinand, 2002; Kock et al., 2010), which are comparable to our obtained $72 \mathrm{~h} \mathrm{EC}_{50}$ of $44 \mu \mathrm{g} / \mathrm{L}$. The same concurrence on experimental $\mathrm{EC}_{50}$ values for algae was obtained for Alachlor and Acetochlor standard samples compared to literature reported values. Our experimental $\mathrm{EC}_{50}$ values were $2.5 \mu \mathrm{g} / \mathrm{L}$ and 6.7 $\mu \mathrm{g} / \mathrm{L}$ for Acetochlor and Alachlor, respectively, which compares with literature values of 0.5-1.4

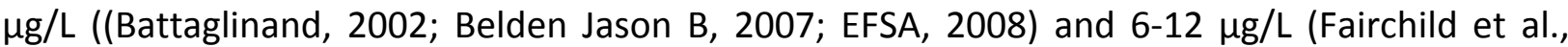

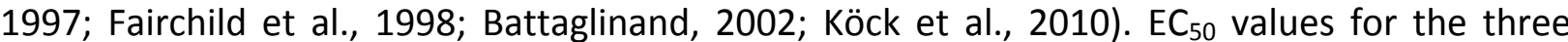
herbicides obtained with the two other bioassays were also concurrent with reported values in the literature as presented in Table 3 and Table S1. The $\mathrm{EC}_{50}$ for the photolyzed samples 
represent the nominal concentration of chloroacetamide. Meaning that for Metolachlor the mixture of degradation products is almost twice as toxic to algae as the parent compound alone, with a nominal concentration of Metolachlor degradation products of only $25.6 \mu \mathrm{g} / \mathrm{L}$ needed in comparison to $44.3 \mu \mathrm{g} / \mathrm{L}$ of the parent compound to cause the same $50 \%$ inhibition of the test parameter.

The solutions of Acetochlor and UV photolysed Acetochlor had almost the same toxicity in the algae tests (table 3, Figure S2). Thus, the generated photoproducts from Acetochlor exhibit the same toxicity as Acetochlor itself. The algal bioassay for Metolachlor and Alachlor (Figure S2) and samples of resultant photolysis products showed statistically significant lower $\mathrm{EC}_{50}$ values for UV-treated samples. This indicates that at least one photolysis product formed by UVtreatment from both Metolachlor and Alachlor is more toxic than the parent chloroacetamides. Theoretically, the results could also be explained by synergistic toxic effects between the degradation products and/or the parent chloroacetamides.

The standardized and extensively used $V$. fisheri based bioassay known as Microtox ${ }^{\circledR}$ was chosen to represent prokaryotic microorganisms. Cytotoxic compounds or inhibitors of any of the enzymes in the bioluminescence mechanism will result in a reduction in luminescence (Dunlap, 1999). Toxicity towards bioluminescent bacteria increased for Metolachlor and Alachlor in irradiated solutions compared to the un-irradiated samples (Table 3), which manifests as significantly lower $\mathrm{EC}_{50}$ values for the UV treated herbicides compared to the two parent compounds.

It was not possible to obtain toxicity data with the bioluminescent bacteria assay for Acetochlor as the highest tested concentration $(200 \mathrm{mg} / \mathrm{L})$ did not exhibit any inhibitory effect. Contrary to this finding, Virag and co-workers (Virág et al., 2007) reported that UV degradation products of Acetochlor have a broad inhibitory effect to various soil microorganisms.

Toxicity assessments using the D. magna bioassay for all three chloroacetamides showed slightly lower $\mathrm{EC}_{50}$ values for the UV-treated samples compared to the parent chloroacetamides. This indicates increased toxicity associated with photolysis products compared to the parent chloroacetamides. In contrast, for the daphnia assay the decreases in $\mathrm{EC}_{50}$ values of photolyzed samples compared to the respective parent parent chloroacetamides were so small that the $95 \%$ confidence intervals overlap indicating that the toxicity increase by the UV-treatment is insignificant for all three chloroacetamides.

\subsection{Comparing toxicity and structures of products of the photo degradation}

Comparison of toxicity development following UV treatment of chloracetamides and the determined molecular structures of photolysis products can be used to draw conclusions about toxicity of the various photodegradation products of chloroacetamides.

The most remarkable result is that all the detected photolysis products of the three chloroacetamides are dechlorinated yet still a very low $\mathrm{EC}_{50}$ towards algae is retained. This indicates that the specific activity of chloroacetamides towards photosynthesizing organisms remains active when the chlorine atom is replaced with a hydroxygroup (photoproduct $A$ ). This result is very significant since it implies a high specific toxicity towards photosynthesising organisms can persist in water following UV treatment due to transformation products of the parent chloroacetamides. This phenomenon would not be revealed by LC-MS or GC-MS based 
analytical methods aimed at parent chloroacetamides, as is commonly employed for monitoring purposes.

UV treatment of Acetochlor generally caused the lowest increase in toxicity observed. The explanation could be that the three most abundant photodegradation products of Acetochlor were photoproducts $\mathrm{D}, \mathrm{J}$ and $\mathrm{K}$ (see Table 2 ) which are formed by cyclizations, eliminating the acetamide structure as the acetate becomes part of the formed ring. Furthermore these three most abundant photoproducts do not contain a phenolic functional group contrary to several of the photodegradation products ( $G$ and $H$ ) formed by UV treatment of Metolachlor for which the highest increase in toxicity was found.

The enhancement of toxicity for photolysis products of Metolachlor towards both algae and bacteria can be attributed to the relatively high abundance of hydroxylated congeners (G1 to G6, see RA in Table 2.) including phenolic compounds. Minor product $\mathrm{H}$, which was detected only in association with Metolachlor is the only other detected phenolic photodegradation product from all three chloroacetamides.

Chloroacetamide based degradation products obtained through anodic Fenton treatment were reported to be resistant to biodegradation and to be toxic (Friedman et al., 2006). Among the major detected degradation products in the Friedman et al. study were phenols and aldehydes, to which this enhanced toxicity was attributed (Friedman et al., 2006). Toxicity of phenols includes respiratory uncoupling and polar narcosis (Shijin, 2003), whereas aldehydes exhibit electrophilic toxicity via the covalent binding to nucleophilic biological macromolecules (Dimitrov et al., 2004).

An increased toxicity of solar photolysis products of Metolachlor towards $V$. fisheri was also reported by Dimou et al (Dimou et al., 2005). These authors attributed the higher toxicity of the photolyzed sample to the formation of 2-ethyl-6-methylaniline as this photoproduct reached its highest concentration in accordance with the toxicity increase. 2-ethyl-6-methylaniline was apparently not formed by the UV-treatment procedure used in our study as it was not found however should be detectable with the applied analytical approach used.

If the increased toxicity of photoproducts from Metolachlor to both algae and bacteria can be ascribed to the phenolic photodegradation product, one could interpret that the marked increase in algal toxicity observed with Alachlor derived degradation products was caused by photoproduct $A$, which is primarily formed by Alachlor (Table 2 and 3 ). One can speculate that the specific toxicity of photoproduct $A$ to algae occurs via the same mechanism as the parent compound since the electronegativity of a chlorine substituent is similar to a hydroxyl group in an organic molecule.

It was reported elsewhere that the decrease of aromaticity during photooxidative degradation of diuron, a substituted urea herbicide, leads to a significant decrease of toxicity (Mestankova et al., 2011). All identified photoproducts in the present study remained aromatic. Thus, the maintained toxicity may be attributed to the persistence of the aromaticity in the photodegradation products .

It was also reported that stable aniline degradation products of chloroacetamides may contribute considerably to environmental risks of pesticide application and that genotoxic effects may arise upon degradation (Osano et al., 2002). Alachlor and Metolachlor solar photodegradation products 2,6-diethylaniline and 2-ethyl-6-methylaniline, which were not 
detected in this study were reported to be 20.9 and 6.3 times more acutely toxic than their corresponding parent compounds, respectively (Osano et al., 2002).

\section{Conclusion}

This work investigated the formation of photoproducts of chloroacetamides that may occur in connection with the use of UV for disinfection of water.

It was found that UV-treatment of chloroacetamides generally produces dechlorinated photodegradation products which were hydroxylated and/or formed through cyclization processes eliminating the acetamide structure.

The mixture of photoproducts formed by UV treatment of each of the three investigated chloroacetamide herbicides; acetochlor, alachlor and metolachlor, were generally found to be more toxic in all three ecotoxicity assays used, but to different degrees and not all at a statistically significant level.

This increase of toxicity can be ascribed to the formation of UV-degradation products of a more toxic nature than the parent compounds. The hydroxyl group which replaces the lost chlorine atom during photolysis seems to enhance toxicity by substitution into the same position of the molecule or substitution into the aromatic ring to form phenolic degradation products.

The high specific toxicity of photodegradation products towards photosynthesising organisms suggests their inclusion in monitoring methods for chloroacetamides together with their parent structures in order to give a more complete picture of contamination levels and risks of toxicity.

\section{Acknowledgement}

The work of the first author was supported partly by the fellowship mobility granted by the Ecole Polytechnique Paris.

The authors would like to gratefully acknowledge Signe Qualmann for her extremely fruitful and helpful assistance and contribution with the ecotoxicity experiments and Cecilie Rendal for providing help and guidance.

\section{References}

Barbash JE, Thelin GP, Kolpin DW, Gilliom RJ. Major herbicides in ground water: Results from the National Water-Quality Assessment. Journal of Environmental Quality 2001; 30: 831-845.

Battaglinand JFaW. Potential toxicity of pesticides measured in midwestern streams to aquatic organisms. Water Science \& Technology 2002; 45: 95-103.

Belden Jason B GRJ, Martin Jeffrey D, and Lydy Michael J. Relative Toxicity and Occurrence Patterns of Pesticide Mixtures in Streams Draining Agricultural Watersheds Dominated by Corn and Soybean Production. Integrated Environmental Assessment and Management 2007; 3: 90-100. 
Böger $\mathrm{P}$, Matthes B, Schmalfuß J. Towards the primary target of chloroacetamides -new findings pave the way. Pest Management Science 2000; 56: 497-508.

Bonnet JL, Bonnemoy F, Dusser M, Bohatier J. Assessment of the potential toxicity of herbicides and their degradation products to nontarget cells using two microorganisms, the bacteria Vibrio fischeri and the ciliate Tetrahymena pyriformis. Environmental Toxicology 2007; 22: 78-91.

Bouchonnet S, Bourcier S, Souissi Y, Genty C, Sablier M, Roche P, et al. GC-MSn andLC$\mathrm{MS} / \mathrm{MS}$ couplings for the identification of degradation products resulting from the ozonation treatment of Acetochlor. J.Mass.Spectrom. 47(4):439-52

Bouchonnet S, Kinani S, Souissi Y, Bourcier S, Sablier M, Roche P, et al. Investigation of the dissociation pathways of metolachlor, acetochlor and alachlor under electron ionization application to the identification of ozonation products. Rapid Communications in Mass Spectrometry 2011; 25: 93-103.

Bourcier S, Poisson C, Souissi Y, Kinani S, Bouchonnet S, Sablier M. Elucidation of the decomposition pathways of protonated and deprotonated estrone ions: application to the identification of photolysis products. Rapid Communications in Mass Spectrometry 2010; 24: 2999-3010.

Boxall ABA, Sinclair CJ. Assessment of the environmental properties and effects of pesticide degradation products. Pesticide Behaviour in Soils and Water 2001; 78: 113-118.

Bull RJ, Reckhow DA, Li X, Humpage AR, Joll C, Hrudey SE. Potential carcinogenic hazards of non-regulated disinfection by-products: Haloquinones, halo-cyclopentene and cyclohexene derivatives, $\mathrm{N}$-halamines, halonitriles, and heterocyclic amines. Toxicology 2011; 286: 1-19.

Cabaj A, Sommer R, Schoenen D. Biodosimetry: Model calculations for u.v. water disinfection devices with regard to dose distributions. Water Research 1996; 30: 10031009.

Cavalier TC, Lavy TL, Mattice JD. Persistence of Selected Pesticides in Ground-Water Samples. Ground Water 1991; 29: 225-231.

Coffinet S, Rifai A, Genty C, Souissi Y, Bourcier S, Sablier M, et al. Characterization of the photodegradation products of metolachlor: structural elucidation, potential toxicity and persistence. Journal of Mass Spectrometry 2012; 47: 1582-1593.

Coupe $\mathrm{RH}$, Blomquist JD. Water-soluble pesticides in finished water of community water supplies. Journal American Water Works Association 2004; 96: 56-68.

Dimitrov S, Koleva Y, Schultz TW, Walker JD, Mekenyan O. Interspecies quantitative structure-activity relationship model for aldehydes: Aquatic toxicity. Environmental Toxicology and Chemistry 2004; 23: 463-470.

Dimou AD, Sakkas VA, Albanis TA. Metolachlor Photodegradation Study in Aqueous Media under Natural and Simulated Solar Irradiation. Journal of Agricultural and Food Chemistry 2005; 53: 694-701.

Dunlap PV. Quorum regulation of luminescence in Vibrio fischeri. J Mol Microbiol Biotechnol 1999; 1: 5-12.

EFSA. Conclusion regarding the peer review of the pesticide risk assessment of the active substance acetochlor, EFSA scientific report 153. EFSA, Parma. 2008.

EU. Council Directive 98/83/EC on the Quality of Water Intended for Human Consumption, European Union,. http://ec.europa.eu/environment/water/water-drink/index_en.html (accessed February 12, 2013). 1998. 
Fairchild JF, Ruessler DS, Carlson AR. Comparative sensitivity of five species of macrophytes and six species of algae to atrazine, metribuzin, alachlor, and metolachlor. Environmental Toxicology and Chemistry 1998; 17: 1830-1834.

Fairchild JF, Ruessler DS, Haverland PS, Carlson AR. Comparative Sensitivity of Selenastrum capricornutum and Lemna minor to Sixteen Herbicides. Archives of Environmental Contamination and Toxicology 1997; 32: 353-357.

Fatta-Kassinos D, Meric S, Nikolaou A. Pharmaceutical residues in environmental waters and wastewater: current state of knowledge and future research. Analytical and Bioanalytical Chemistry 2011a; 399: 251-275.

Fatta-Kassinos D, Vasquez MI, Kümmerer K. Transformation products of pharmaceuticals in surface waters and wastewater formed during photolysis and advanced oxidation processes - Degradation, elucidation of byproducts and assessment of their biological potency. Chemosphere 2011b; 85: 693-709.

Friedman CL, Lemley AT, Hay A. Degradation of Chloroacetanilide Herbicides by Anodic Fenton Treatment. Journal of Agricultural and Food Chemistry 2006; 54: 2640-2651.

Gascuel-Odoux C, Aurousseau P, Cordier M-O, Durand P, Garcia F, Masson V, et al. A decision-oriented model to evaluate the effect of land use and agricultural management on herbicide contamination in stream water. Environmental Modelling \&amp; Software 2009; 24: 1433-1446.

Hansen KMS, Andersen HR. Energy Effectiveness of Direct UV and UV/H2O2 Treatment of Estrogenic Chemicals in Biologically Treated Sewage. International Journal of Photoenergy 2012; 2012: 9.

Hijnen WAM, Beerendonk EF, Medema GJ. Inactivation credit of UV radiation for viruses, bacteria and protozoan (oo)cysts in water: A review. Water Research 2006; 40: 3-22.

Hladik ML, Bouwer EJ, Roberts AL. Occurrence and treatment of neutral chloroacetamide degradates in midwestern US drinking water. Abstracts of Papers of the American Chemical Society 2005a; 229: U69-U69.

Hladik ML, Bouwer EJ, Roberts AL. Neutral degradates of chloroacetamide herbicides: Occurrence in drinking water and removal during conventional water treatment. Water Research 2008; 42: 4905-4914.

Hladik ML, Hsiao JJ, Roberts AL. Are neutral chloroacetamide herbicide degradates of potential environmental concern? Analysis and occurrence in the upper Chesapeake Bay. Environmental Science \& Technology 2005b; 39: 6561-6574.

Hollender, J., Zimmermann, S.G., Koepke, S., Krauss, M., McArdell, C.S., Ort, C., Singer,

H., Von Gunten, U., Siegrist, H., 2009. Elimination of organic micropollutants in a municipal wastewater treatment plant upgraded with a full-scale post-ozonation followed by sand filtration. Environmental Science and Technology 43(20), 7862-7869.

Horvat AJM, Babić S, Pavlović DM, Ašperger D, Pelko S, Kaštelan-Macan M, et al. Analysis, occurrence and fate of anthelmintics and their transformation products in the environment. TrAC Trends in Analytical Chemistry 2012; 31: 61-84.

ISO6341. Water quality -- Determination of the inhibition of the mobility of Daphnia magna Straus (Cladocera, Crustacea) -- Acute toxicity test. International Organization for Standardization, Switzerland 1996.

ISO8692. Water quality -- Freshwater algal growth inhibition test with unicellular green algae. International Organisation for Standardisation, Switzerland 2004. 
ISO11348-3. Water quality -- Determination of the inhibitory effect of water samples on the light emission of Vibrio fischeri (Luminescent bacteria test) -- Part 3: Method using freezedried bacteria. International Organization for Standardization, Switzerland 1998.

Kiely T, Donaldson D, Grube A. Pesticide Industry Sales and Usage: 2000 and 2001 Market Estimates Washington, DC : U.S. Environmental Protection Agency (USEPA) 2002.

Kock M, Farre M, Martinez E, Gajda-Schrantz K, Ginebreda A, Navarro A, et al. Integrated ecotoxicological and chemical approach for the assessment of pesticide pollution in the Ebro River delta (Spain). Journal of Hydrology 2010; 383: 73-82.

Konstantinou, I.; Hela, D. \& Albanis, T. (2006). The status of pesticide pollution in surface waters (rivers and lakes) of Greece. Part I. Review on occurrence and levels,

Environmental Pollution, Vol. 141, No. 3, 555-570, ISSN 0269-7491

Kosjek T, Andersen HR, Kompare B, Ledin A, Heath E. Fate of Carbamazepine during Water Treatment. Environmental Science \& Technology 2009; 43: 6256-6261.

Kosjek T, Heath E. Applications of mass spectrometry to identifying pharmaceutical transformation products in water treatment. Trac-Trends in Analytical Chemistry 2008; 27: 807-820.

Lewis SE, Brodie JE, Bainbridge ZT, Rohde KW, Davis AM, Masters BL, et al. Herbicides: A new threat to the Great Barrier Reef. Environmental Pollution 2009; 157: 2470-2484.

Li XY, Su ZC, Li X, Zhang CG, Zhang HW. Assessing the effects of acetochlor on soil fungal communities by DGGE and clone library analysis. Ecotoxicology 2010; 19: 1111-1116.

Matthes B, Boger P. Chloroacetamides affect the plasma membrane. Zeitschrift Fur Naturforschung C-a Journal of Biosciences 2002; 57: 843-852.

Mestankova H, Escher B, Schirmer K, von Gunten U, Canonica S. Evolution of algal toxicity during (photo)oxidative degradation of diuron. Aquatic Toxicology 2011; 101: 466-473.

Osano O, Admiraal W, Klamer HJC, Pastor D, Bleeker EAJ. Comparative toxic and genotoxic effects of chloroacetanilides, formamidines and their degradation products on Vibrio fischeri and Chironomus riparius. Environmental Pollution 2002; 119: 195-202.

Reichenberger S, Bach M, Skitschak A, Frede H-G. Mitigation strategies to reduce pesticide inputs into ground- and surface water and their effectiveness; A review. Science of The Total Environment 2007; 384: 1-35.

Richardson S.D., Disinfection by-products and other emerging contaminants in drinking water, TrAC Trends Anal Chem 22, 2003, 666-684.

Richardson SD. Environmental mass spectrometry: Emerging contaminants and current issues. Analytical Chemistry 2008; 80: 4373-4402.

Richardson SD, Plewa MJ, Wagner ED, Schoeny R, DeMarini DM. Occurrence, genotoxicity, and carcinogenicity of regulated and emerging disinfection by-products in drinking water: A review and roadmap for research. Mutation Research/Reviews in Mutation Research 2007; 636: 178-242.

Rocha C, Pappas EA, Huang C-h. Determination of trace triazine and chloroacetamide herbicides in tile-fed drainage ditch water using solid-phase microextraction coupled with GC-MS. Environmental Pollution 2008; 152: 239-244.

Shijin R. Phenol mechanism of toxic action classification and prediction: a decision tree approach. Toxicology Letters 2003; 144: 313-323.

Souissi Y, Bourcier S, Bouchonnet S, Genty C, Sablier M. Estrone direct photolysis: Byproduct identification using LC-Q-TOF. Chemosphere 2012; 87(2):185-93..

Ternes TA, Meisenheimer M, McDowell D, Sacher F, Brauch HJ, Gulde BH, et al. Removal of pharmaceuticals during drinking water treatment. Environmental Science \& Technology 2002; 36: 3855-3863. 
USEPA. Final Contaminant Candidate List 3 Chemicals: Identifying the Universe. U.S. Environmental Protection Agency. Available from: http://www.epa.gov/safewater/ccl/ccl3.html\#chemical.Available from: http://www.epa.gov/safewater/ccl/ccl3.html\#chemical. 2009.

Virág D, Naár Z, Kiss A. Microbial Toxicity of Pesticide Derivatives Produced with UVphotodegradation. Bulletin of Environmental Contamination and Toxicology 2007; 79: 356-359.

Wei J, Ye B, Wang W, Yang L, Tao J, Hang Z. Spatial and temporal evaluations of disinfection by-products in drinking water distribution systems in Beijing, China. Science of the Total Environment 2010; 408: 4600-4606 


\section{Supporting Information}

\section{Detailed experimental sections}

1- Chemical analysis conditions

1-1- GC-MS experimental condition

1-2- LC-MS experimental condition

2- Ecotoxicity bioassays conditions

1.1. Daphnia magna acute immobilization tests

1.2. Pseudokirchneriella subcapitata growth inhibition test

1.3. Bioluminescence inhibition test of Vibrio fischeri

\section{Supplementary tables and figures related to exotoxicity}

List of tables:

Table S1 Literature survey of $50 \%$ effective concentrations $\left(\mathrm{EC}_{50} \mathrm{~s}\right)$ of the investigated herbicides with the three used ecotoxicity tests

\section{List of figures:}

Figure S1 Concentration-response curves obtained for the three herbicides and their photodegradates with Daphnia magna toxicity test.

Figure S2: Concentration-response curves obtained for the three herbicides and their photodegradates with Pseudokirchneriella subcapitata growth inhibition test

Figure S3: Concentration-response curves obtained for metolachlor and alachlor solutions and their photodegradates with Vibrio fischeri bioluminescence inhibition test

\section{Details on structure determination of photolysis products}

List of figures:

Figure S4: Chromatograms of photolysed and non-photolyzed Alachlor and acetochlor in GC-MS.

Figure S5: Chromatograms obtained in LC-MS experiments: Extracted photoproducts and acetochlor ions

Figure S6: Structure of deuterated alachlor and acetochlor showing the positions that were deuterated.

Figure S7: Fragmentation pathway for compound A in LC-MS

Figure S8: The fragmentation pathway of compounds $\mathrm{E}$ and $\mathrm{F}$.

\section{List of tables:}

Table S2: Molecular weight, retention time, chemical structure and main $\mathrm{MS}^{\mathrm{n}}$ transitions obtained by GC-MS for alachlor photoproducts.

Table S3: Molecular weight, retention time, chemical structure and main daughter ions for the degradation product A for alachlor and acetochlor in LC-MS.

\section{References}




\section{Chemical analysis conditions}

\section{1-1- GC-MS experimental conditions:}

All experiments were carried out by automatically injecting $1.0 \mu \mathrm{L}$ of sample in the splitless mode at a rate of $50 \mu \mathrm{L} \cdot \mathrm{s}^{-1}$. Helium gas was used as a carrier at a flow rate of $1.4 \mathrm{~mL} \cdot \mathrm{min}^{-1}$. The oven temperature started at $50^{\circ} \mathrm{C}$, was held for $0.5 \mathrm{~min}$, then increased incrementally $10^{\circ} \mathrm{C} \cdot \mathrm{min}^{-}$ ${ }^{1}$ up to $320^{\circ} \mathrm{C}$ where it was held for $7.5 \mathrm{~min}$. The total duration of GC analysis was $35 \mathrm{~min}$. The manifold, ion trap electrodes and transfer line temperatures were set at $120^{\circ} \mathrm{C}, 220^{\circ} \mathrm{C}$ and 300 ${ }^{\circ} \mathrm{C}$, respectively. Calibration of the mass spectrometer was automatically performed using ions resulting from electron ionization (EI) of perfluorotributylamine. Chemical ionization (CI) experiments were carried out using methanol as the reagent gas. Spectra were recorded using the automatic gain control (AGC) function with a target value of 20.000 in EI, 5000 in CI. In all experiments emission current was set to $10 \mu \mathrm{A}$ and the electron multiplier voltage to $1850 \mathrm{~V}$. Full scan mass spectra were recorded on a scanning range from $\mathrm{m} / \mathrm{z} 50$ to $\mathrm{m} / \mathrm{z} 450$. An isolation window of one mass unit was employed for multiple stage mass spectrometry ( $\mathrm{MS}^{\mathrm{n}}$ ) experiments. In $\mathrm{MS}^{\mathrm{n}}$, precursor ions were stored with a $\mathrm{q}_{\mathrm{z}}$ stability parameter of 0.30 , and fragmented by collision induced dissociation with different activation energy values ranging from 0.2 to $1.0 \mathrm{~V}$ using the resonant excitation mode.

\section{1-2- LC-MS experimental conditions:}

The $\mathrm{CH}_{3} \mathrm{CN}+$ formic acid $(0.1 \%)(\mathrm{A}) / \mathrm{H}_{2} \mathrm{O}+$ formic acid $(0.1 \%)$ (B) gradient used was the following: $40 \% \mathrm{~A} / 60 \% \mathrm{~B}$ from 0 to $11.0 \mathrm{~min}, 100 \% \mathrm{~A}$ from 11.1 to $20.0 \mathrm{~min}$ and $40 \% \mathrm{~A} / 60 \%$ B from $20.1 \mathrm{~min}$ to $30.0 \mathrm{~min}$. A constant flow of $0.2 \mathrm{~mL} \cdot \mathrm{min}^{-1}$ was used. The volume of injected samples was $2 \mu \mathrm{L}$. The electrospray interface was operated under the following conditions: capillary voltage $2.6 \mathrm{kV}$, cone voltage $20 \mathrm{~V}$, source temperature $100{ }^{\circ} \mathrm{C}$, desolvation temperature $450^{\circ} \mathrm{C}$, and collision energy 5 and $15 \mathrm{eV}$. Accurate mass measurements (four decimal places) were carried out at a resolution higher than 5000 (full width at half maximum) using an independent reference spray (phosphoric acid) via the Lockspray interface to ensure accuracy. For accurate mass measurements, analyses were acquired using $\mathrm{W}$-mode and using an independent reference spray via the LockSpray interface to ensure accuracy. Phosphoric acid was used as the lock mass at a flow rate of $10 \mu \mathrm{Lmin}^{-1}$. The LockSpray frequency was set at $10 \mathrm{~s}$ and data for the reference compounds were averaged over 10 spectra $\min ^{-1}$. The accurate mass and the elemental composition for all ions are obtained using instrument software MassLynx. The ions used for the mass correction were $\mathrm{m} / \mathrm{z} 294.9685$ and 196.9616 depending on the ions. All the measured mass were determined with an error $<5 \mathrm{ppm}$. 


\section{Ecotoxicity bioassays conditions}

\section{2-1- Daphnia magna acute immobilization tests}

This aquatic animal is extensively used as a test organism in aquatic toxicology due to their small size, short life cycle and amenability to lab culture. Static acute 24-48 h assays were conducted according to internationally accepted Standard Methods (ISO6341, 1996). A healthy culture of Daphnia magna is used as the source of mother organism. The day before the start of the test, the mother cultures were cleaned up and all animals except the mother animals were removed. Thus, the neonates that were born in the night and were less than $24 \mathrm{~h}$ were used for the test. Immobility at $24 \mathrm{~h}$ and $48 \mathrm{~h}$ is the bioassay endpoint, assumed to be equivalent to mortality. In each test a control and 5 (or 6) test concentrations were included in each sample. Each concentration was tested using four replicate vessels with 5 neonates per replicate. Daphnia neonates exposed to the control and different concentrations were incubated in darkness at $20^{\circ} \mathrm{C}$. After $24 \mathrm{~h}$ and $48 \mathrm{~h}$ of exposure the number of immobilized organisms were determined. The EC50 is determined as the concentrations producing 50\% of immobilization as described below.

\section{2-2- Pseudokirchneriella subcapitata growth inhibition test}

A growth inhibition test using the green algae Pseudokirchneriella subcapitata was performed according to ISO 8692 (ISO8692, 2004). A series of dilutions of parent compound and photolyzed solution samples were prepared. 10-ml algal cultures in 20-ml growth vials capped with lids were used with a small hole drilled to allow equilibration with atmospheric $\mathrm{CO}_{2}$ while minimizing any volatilization losses from solution. The sample dilutions and the controls were inoculated with the microalgae from the concentrated suspension to obtain $5-10 \cdot 10^{3}$ cells $/ \mathrm{mL}$ as the start algae density. Tests were conducted in triplicate with six control replicates and a $\mathrm{pH}$ of approximately 7.8 . The samples were incubated for $72 \mathrm{~h}$ at $20^{\circ} \mathrm{C}$, with a continuous illumination of 10,000 lux from fluorescent tubes. The algal biomass was measured by fluorescence on acetone extracts of samples taken immediately after addition of the algae $(0 \mathrm{~h})$, after 24,48 and $72 \mathrm{~h}$ of exposure with a Hitachi F-2000 Fluorescence Spectrophotometer (Hitachi, Japan) with excitation light at $430 \mathrm{~nm}$ and emission light at $671 \mathrm{~nm}$. Samples from the vials were extracted with acetone $24 \mathrm{~h}$ prior to the fluorescence measurements. The fluorescence was used directly for calculation of growth rates in each vial.

\section{2-3- Bioluminescence inhibition test of Vibrio fischeri}

The experimental procedure for conducting the bacterial bioluminescence assay is based on the ISO protocol (ISO11348-3, 1998). The analysis was carried out with all dilution and reagents maintained at $15^{\circ} \mathrm{C}$. A working solution of luminescent bacteria was prepared by reconstituting a vial of frozen lyophilized Vibrio fishier cells using $12.5 \mathrm{ml}$ of the reagent diluent provided by the manufacturer. The reconstituted solution was equilibrated for a minimum of 30 minutes at $4{ }^{\circ} \mathrm{C}$. The hydrated cell suspension is usable for several hours when kept chilled. The osmolality is adjusted in order to obtain $2 \% \mathrm{w} / \mathrm{v} \mathrm{NaCl}$ in each solution or sample. Bacterial reagents are reconstituted just prior to the analysis and the pre-incubation times follow standard protocols. In all measures, the percent of inhibition (\% I) was determined by comparing the relative response 
of the control to that of the diluted sample. Each dilution was tested in duplicate and performed at $15^{\circ} \mathrm{C}$.

A dilution series of the samples to be analysed were prepared in sodium chloride solution ( $2 \%$ $\mathrm{NaCl}$ ). Different concentration intervals were used for the tested chemicals depending on the expected EC50. For the photolyzed solutions, a larger concentration range was adopted as the EC50 values were unknown. The sample $\mathrm{pH}$ values were approximately 7 . A fixed amount of bacteria (100 $\mu \mathrm{l}$ of the reconstituted cell suspension) was added to the dilution vials. Luminescence was measured at time zero (before addition of test solution) and then after 5, 15 and $30 \mathrm{~min}$ and compared to the measured value of a bacterial control. The concentration of toxicants in the test which causes a $50 \%$ inhibition of bioluminescence after exposure for 5,15 or 30 min was designated as the EC50 value. The measurements of bioluminescence were made using the luminometer Luminoskan TL Plus (Thermo lab system).

\section{2-4- Statistical analysis}

Due to the different nature of the endpoints (continued responses in algal and biotox tests and quantal responses in the Daphnia test), the ecotoxicity test results were treated with different statistical methods.

Specific algal growth rates were calculated from the exponential increase in cell density in each replicate using the standard formula shown in ISO 8692 (ISO8692, 2004) assuming exponential growth during the 72-h duration of the assays. The inhibition of growth rates are calculated as percentages of the mean growth rate of the controls and plotted against the logarithm of the concentration. Further data treatment and calculation of log-norm and Weibull concentrationresponse curves and estimation of EC50 and EC10 with 95\% confidence intervals were carried out on a Windows-based computer program (Christensen et al., 2009).

The relative inhibition of Vibrio fischeri bioassays were determined using equations (1) and (2) corresponding respectively to the correction factor for each measuring time (KF5, KF15 and KF30) and the relative response (REL\% xmin). The dose-response curves exhibiting the bioluminescence inhibition were generated by the same statistical program as the algae growth inhibition. Further treatment of data was performed with the program previously mentioned (Christensen et al., 2009).

$$
\mathrm{KF}_{\mathrm{x}}=\mathrm{IC}_{\mathrm{x}} / \mathrm{IC}_{0}
$$

where $\mathrm{ICx}=$ Average luminescence of control samples after contact time (x min)

$$
\mathrm{REL} \% \mathrm{xmin}=\left[\mathrm{IT}_{\mathrm{x}} / \mathrm{KF}_{\mathrm{x}} \times \mathrm{IT}_{0}\right] \times 100
$$

where ITx $=$ Luminescence intensity of test sample after contact time Daphnia magna toxicity assay results were analyzed statistically with a probit procedure using Toxcalc ${ }^{\circledR}$ (version 5.0, ToxCalc. 2001. Tidepool Scientific, LLC. McKinleyville, CA, USA). Median effective concentrations and 95\% fiducial limits as well as probit values were calculated. 


\section{Tables and Figures related to exotoxicity}


Table S1 Literature survey of fifty percent effective concentration $\mathrm{EC}_{50} \mathrm{~S}$ of the investigated herbicides with the three used ecotoxicity tests

\begin{tabular}{|c|c|c|c|c|c|c|}
\hline & \multicolumn{2}{|c|}{ Alachlor } & \multicolumn{2}{|c|}{ Acetochlor } & \multicolumn{2}{|c|}{ Metolachlor } \\
\hline Bioassay & EC 50 & Reference & EC 50 & Reference & EC 50 & Reference \\
\hline \multirow{5}{*}{$\begin{array}{c}\text { Pseudokirchneriella } \\
\text { subcapitata } \\
\mathrm{EC}_{50} \mu \mathrm{g} / \mathrm{L}\end{array}$} & 10 & Köck et al., 2010 & 0.52 & EFSA, 2008 & 55 & $\begin{array}{l}\text { Köck et al., } \\
2010\end{array}$ \\
\hline & $64-9$ & Fairchild et al., 1997 & 1.4 & $\begin{array}{l}\text { Belden Jason B } \\
2007\end{array}$ & 57 & $\begin{array}{l}\text { Battaglinand } \\
\quad, 2002\end{array}$ \\
\hline & 5.9 & Battaglinand 2002 & 1.43 & Battaglinand, 2002 & $8472-95$ & $\begin{array}{l}\text { Fairchild et } \\
\text { al., } 1998\end{array}$ \\
\hline & 10 & $\begin{array}{l}\text { Fairchild et al., } \\
1998\end{array}$ & 2.50 & Own results & 44.3 & Own results \\
\hline & 6.69 & Own results & & & & \\
\hline \multirow{3}{*}{$\begin{array}{l}\text { Daphnia magna } \\
\qquad \mathrm{EC}_{50} \mathrm{mg} / \mathrm{L}\end{array}$} & 10 & Köck et al., 2010 & 7.4 & EFSA, 2008 & 23.5 & $\begin{array}{l}\text { Köck et al., } \\
2010\end{array}$ \\
\hline & 7.50 & Own results & 8.2 & $\begin{array}{l}\text { Belden Jason B } \\
2007\end{array}$ & \multirow[t]{2}{*}{22.3} & Own results \\
\hline & & & 6.29 & Own results & & \\
\hline \multirow{4}{*}{$\begin{array}{c}\text { Vibrio Fischeri } \\
\mathrm{EC}_{50} 15 \mathrm{~min} \mathrm{mg} / \mathrm{L}\end{array}$} & 160 & Köck et al., 2010 & & \multirow{4}{*}{ NA* } & 17 & \multirow{4}{*}{$\begin{array}{l}\text { Köck et al.., } \\
2010 \\
\text { Own results }\end{array}$} \\
\hline & $206 \pm 39$ & Bonnet et al., 2007 & & & \multirow{3}{*}{17.1} & \\
\hline & 105.4 & Lapertot et al.., 2008 & & & & \\
\hline & 155 & Own results & & & & \\
\hline
\end{tabular}

*NA: Not Available 
Metolachlor
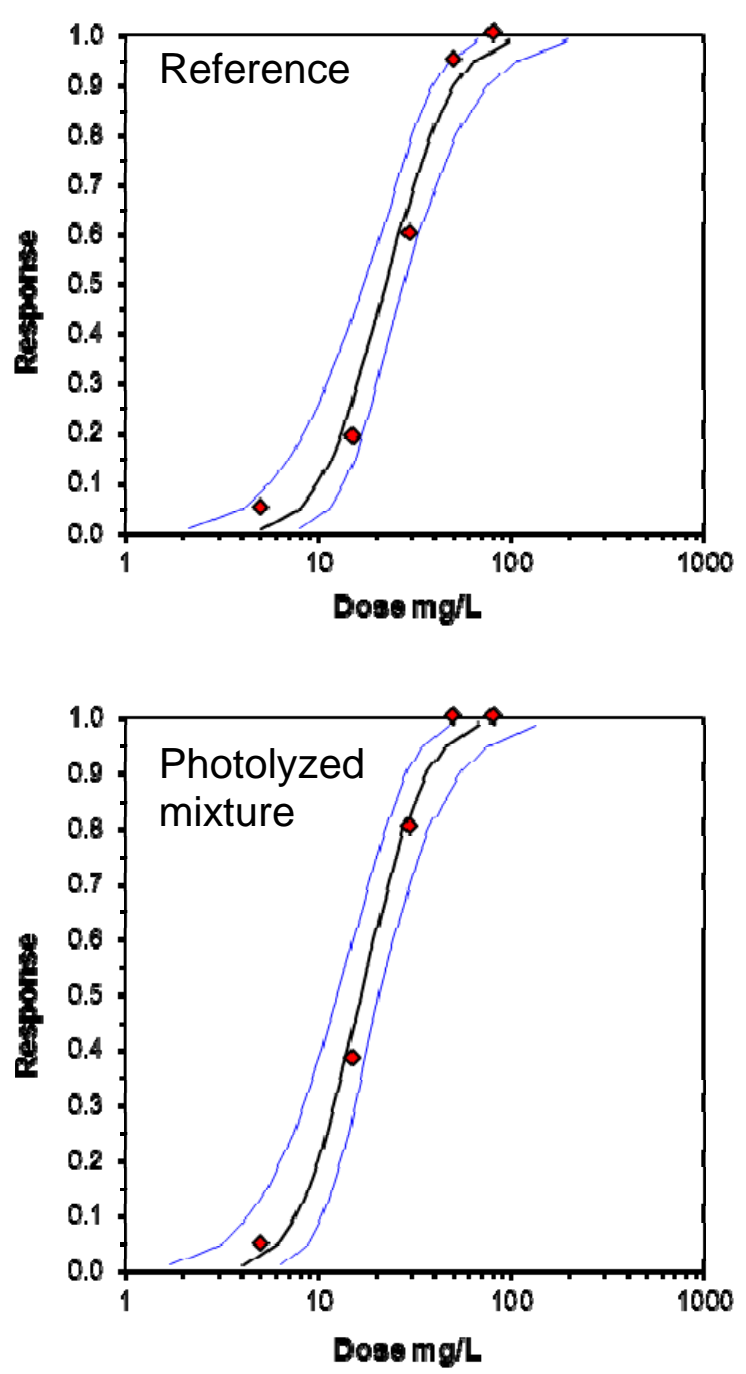

Acetochlor
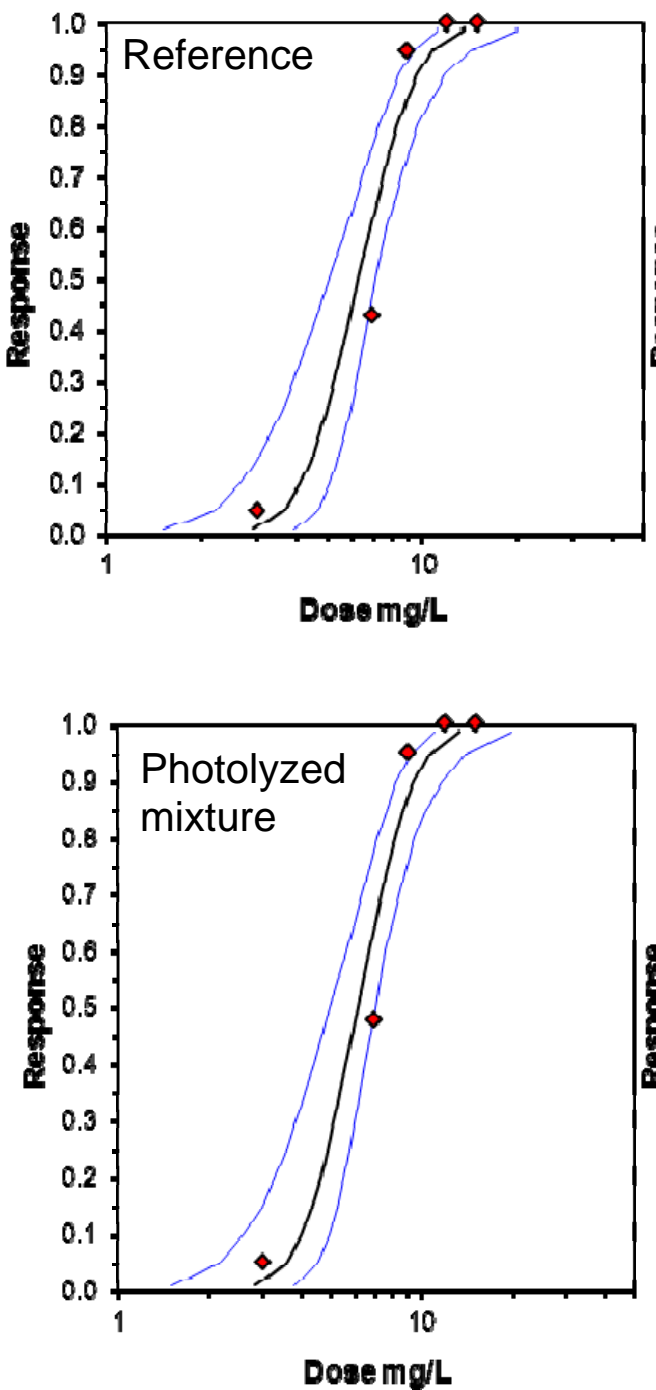

Alachlor
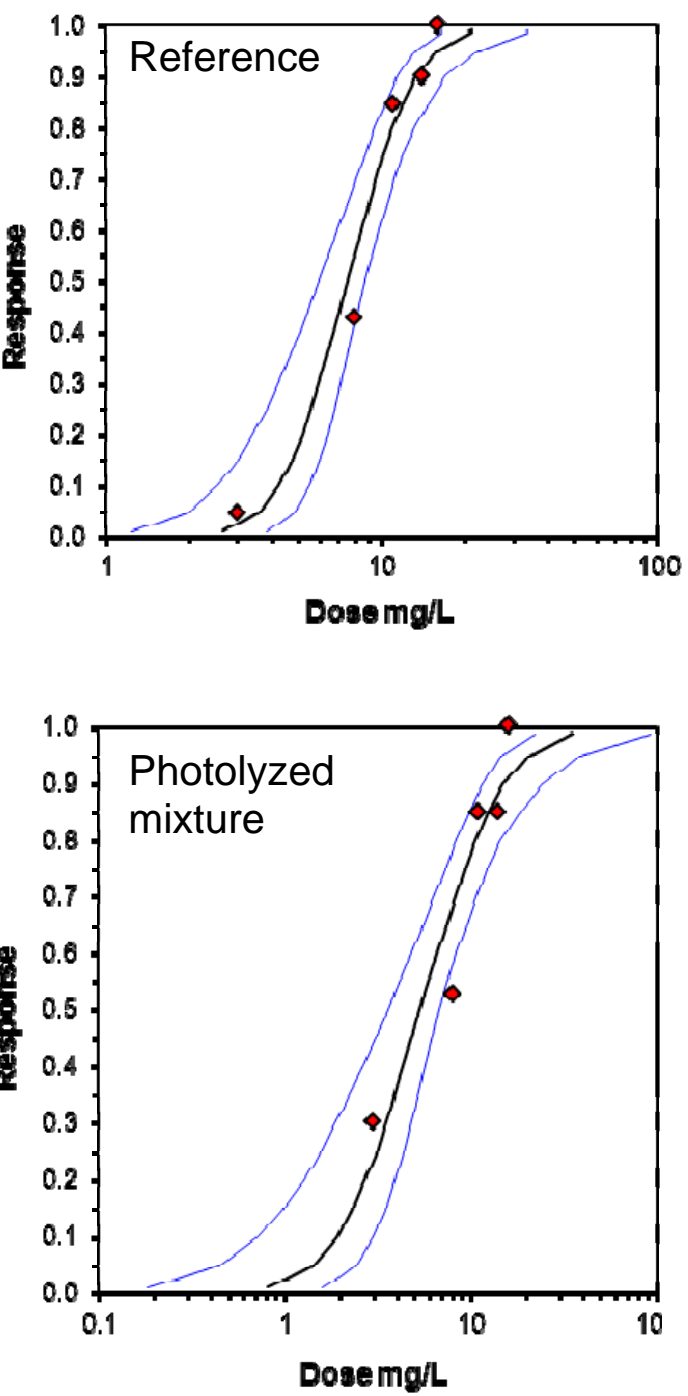

Figure S1 Response-dose curves obtained for the three herbicides and their photodegradates obtained with Daphnia magna toxicity test. Line in blue indicate the upper and lower 95\% fiducial limits, line in black represents the optimal fit. 
Effect curve fit : Metolchlor Reference Solution

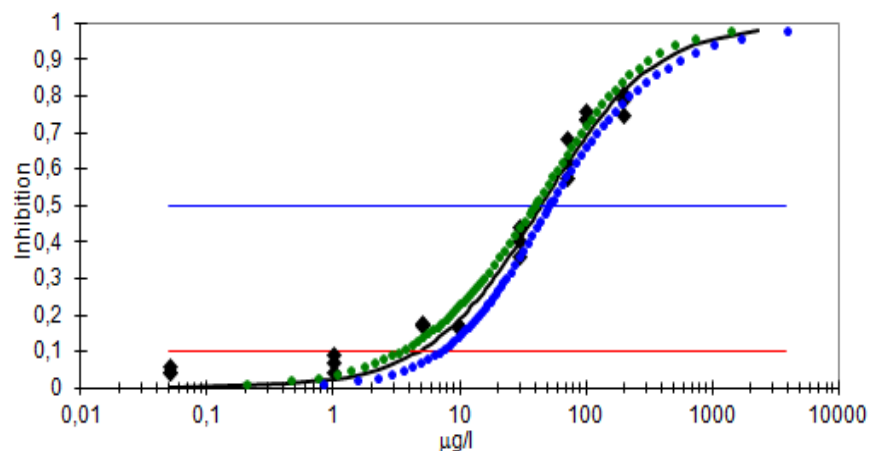

Effect curve fit : Metolchlor Photolyzed Solution

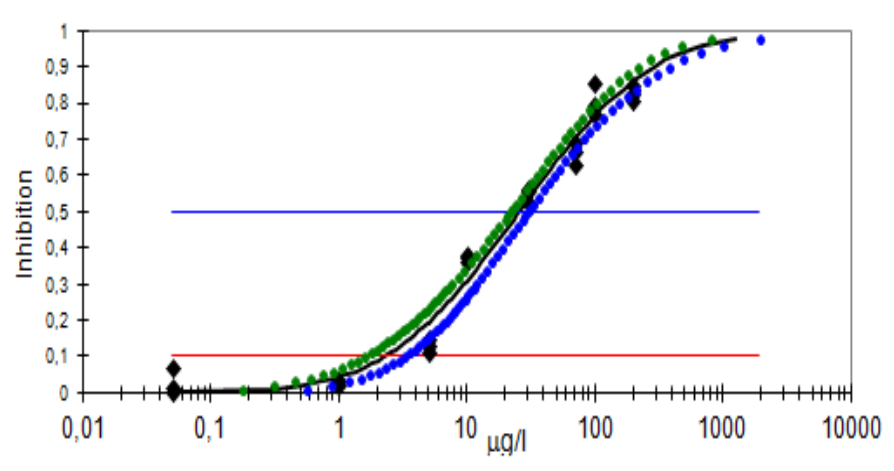

Effect curve fit : Acetochlor Reference Solution

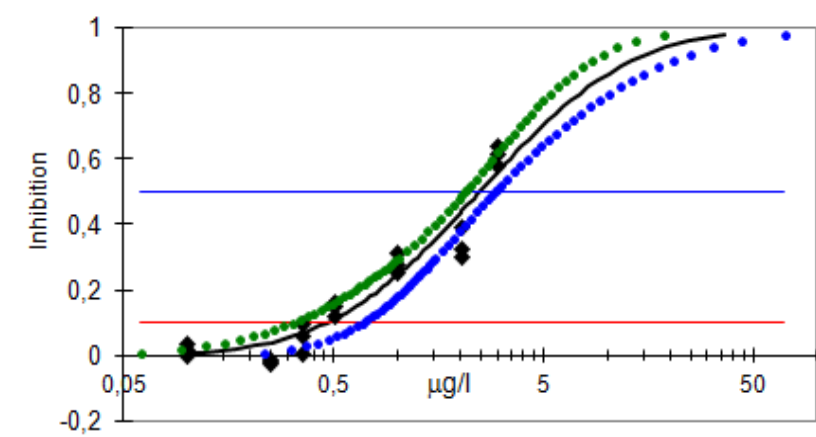

Effect curve fit : Acetochlor Photolyzed Solution

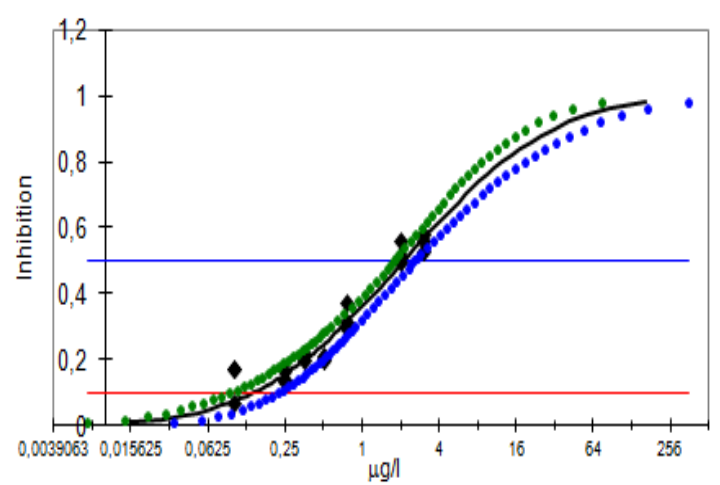

Effect curve fit : Alachlor Reference solution

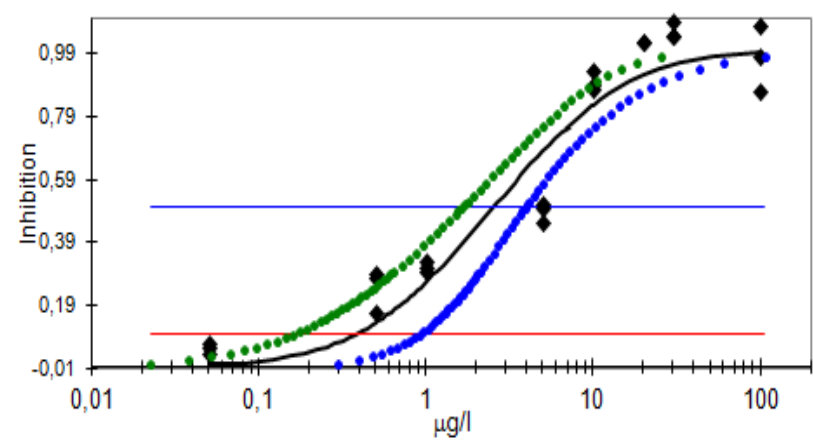

Effect curve fit : Alachlor Photolyzed solution

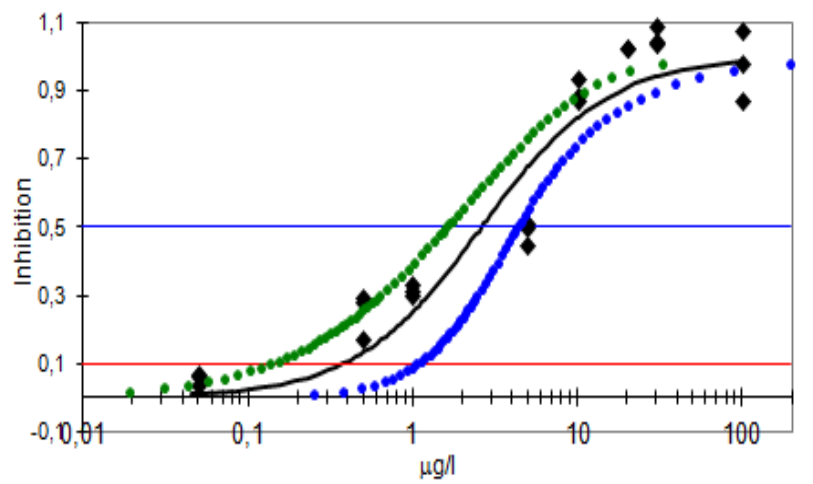

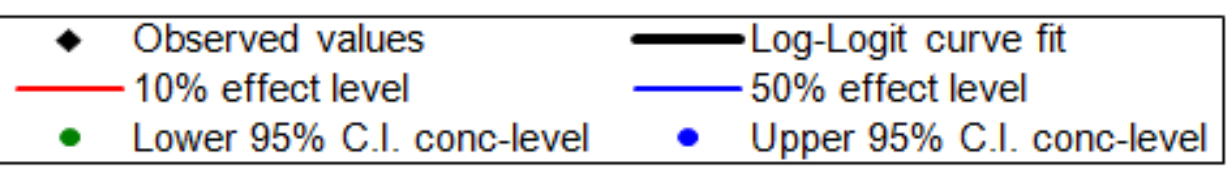

Figure S2 Response-dose curves and confidence intervals obtained for the three herbicides and their photodegradates obtained with Pseudokirchneriella subcapitata growth inhibition test. 
Effect curve fit : Metolchlor Reference Solution

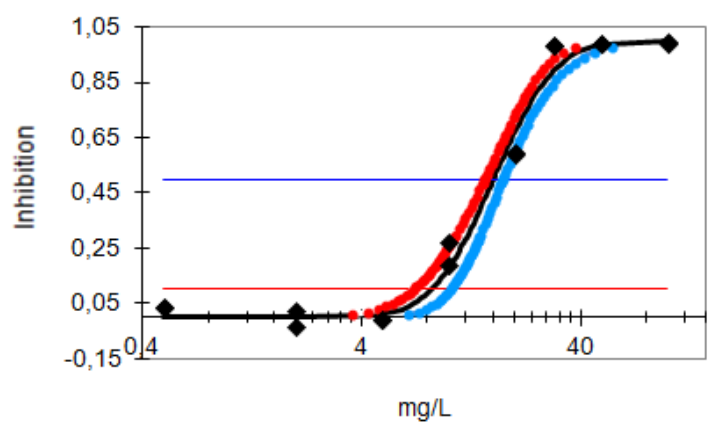

Effect curve fit : Metolchlor Photolyzed Solution

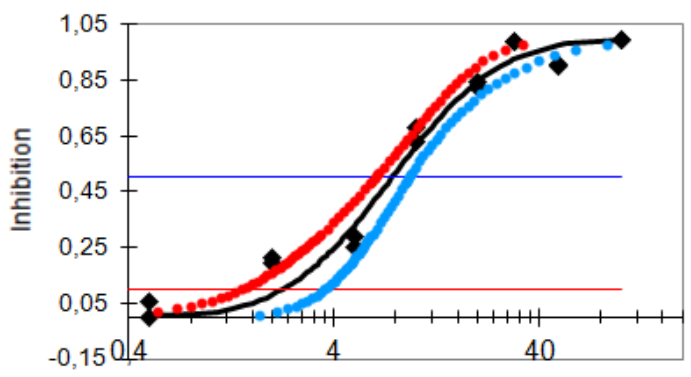

$\mathrm{mg} / \mathrm{L}$
Effect curve fit : Alachlor Reference solution

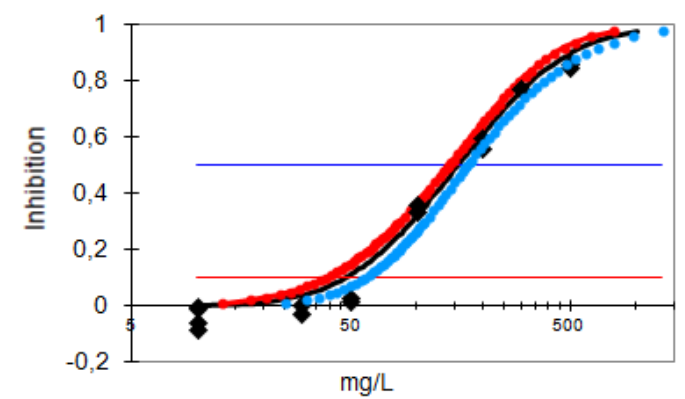

Effect curve fit : Alachlor Photolyzed solution

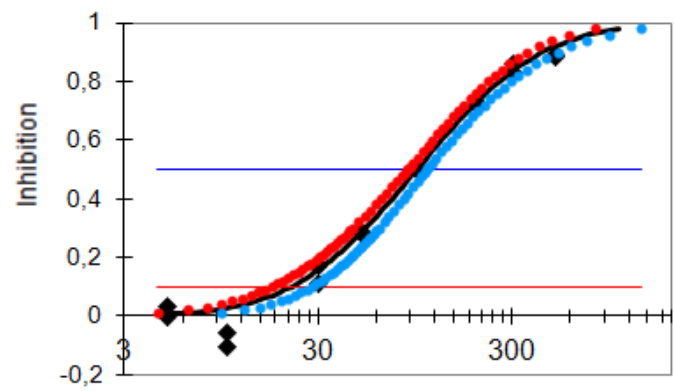

$\mathrm{mg} / \mathrm{L}$

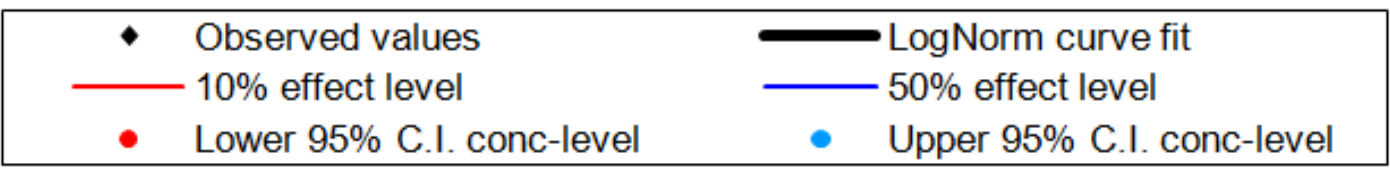

Figure S3 Response-dose curves and confidence intervals for reference and photolyzed metolachlor and alachlor solutions with Vibrio fischeri bioluminescence inhibition test. 


\section{Details on structure determination of photolysis products}

A)

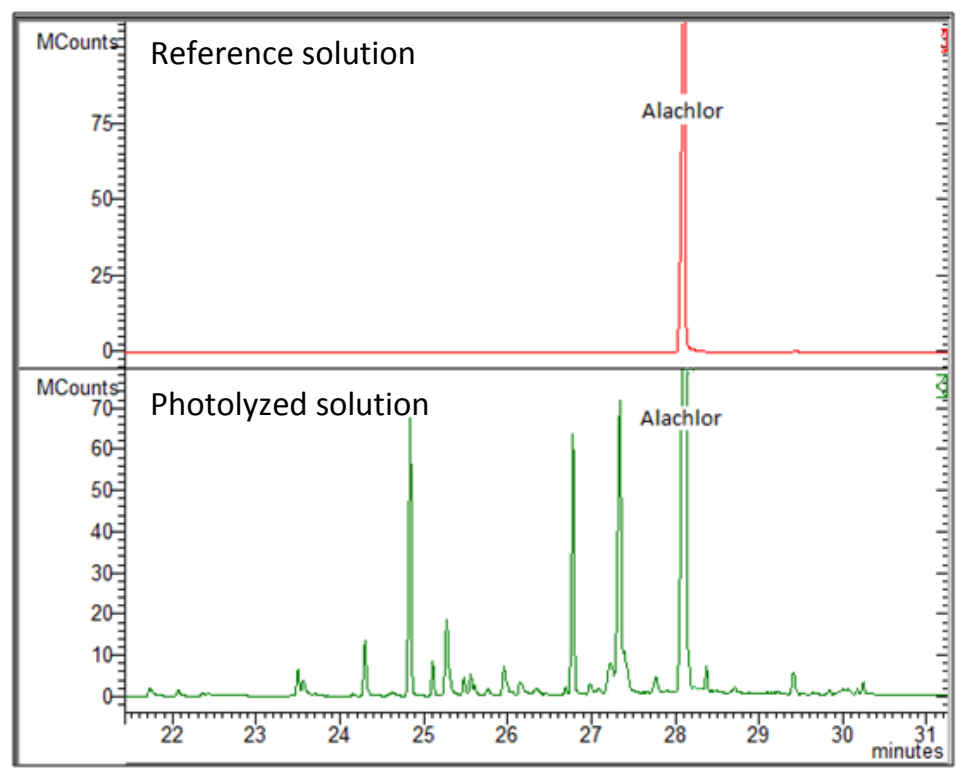

B)

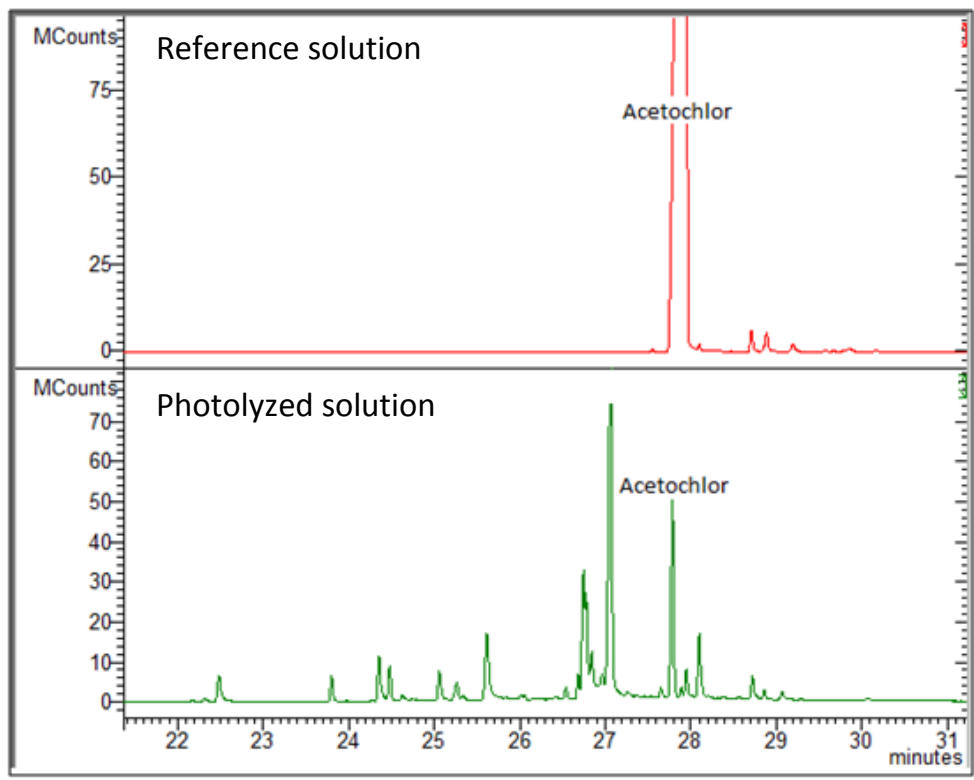

Figure S4: Chromatograms of photolysed and non-photolyzed Alachlor (A) and acetochlor (B) solutions obtained in GC-MS analysis. The similar chromatograms on metolachlor is published in Coffinet et al., 2012. 

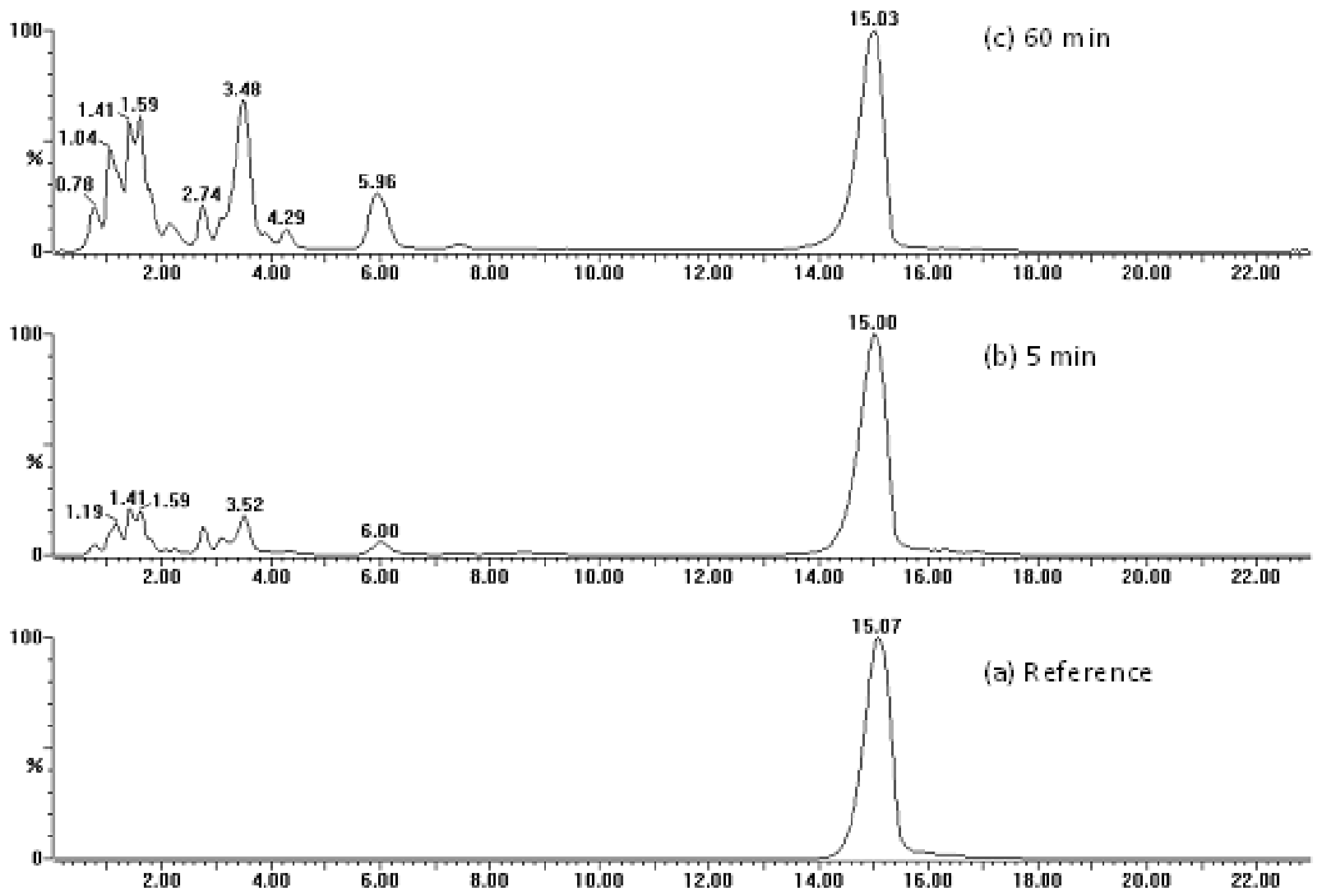

Figure S5: Chromatograms obtained in LC-MS experiments: Extracted photoproducts and acetochlor ions chromatograms for (a) acetochlor reference solution (b) irradiated (5 min) acetochlor and (c) irradiated (60 min) acetochlor solution.

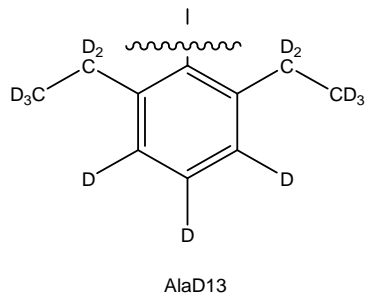

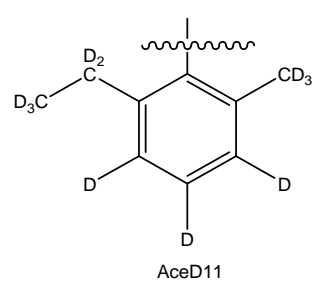

Figure S6: Structure of deuterated alachlor and acetochlor showing the positions that were deuterated.

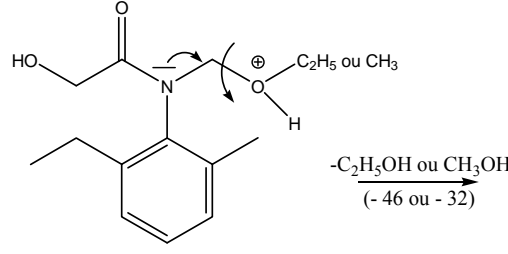

Acé $\mathrm{MH}^{+} \mathrm{m} / \mathrm{z} 252$

$-\mathrm{CH}_{2} \mathrm{O}$

Acé $\mathrm{m} / \mathrm{z} 222$<smiles></smiles>

Acé $\mathrm{m} / \mathrm{z} 206$<smiles>COc1ccccc1</smiles>

Acé $m / 2176$<smiles>C=CC(C)Cc1cccc(C)c1NC</smiles>
Acé m/z 148
Ala m/z 162

Figure S7: Fragmentation pathway for compound A in LC-MS. 


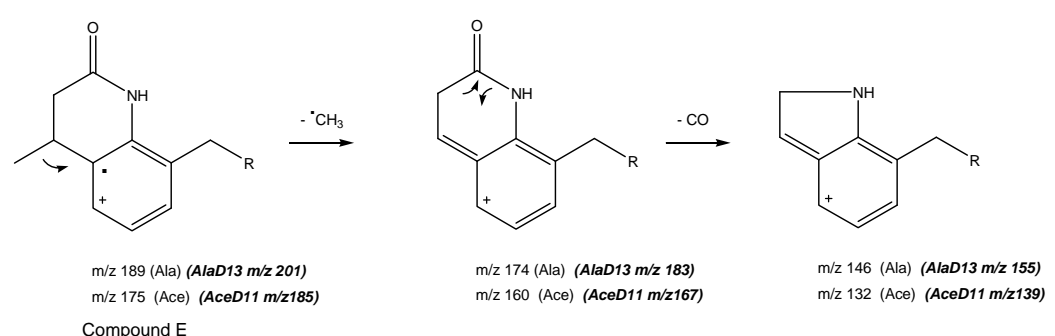

Compound $\underline{E}$

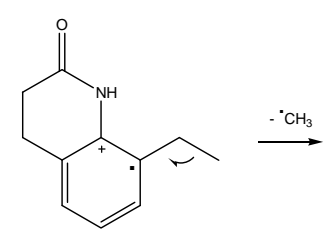

m/2 175 (Ace) (AceD11 m/2185)

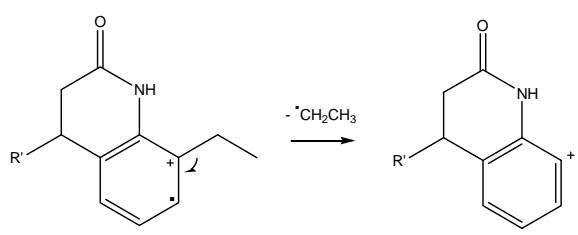

m/z 189 (Ala) (AlaD13 m/z 201)

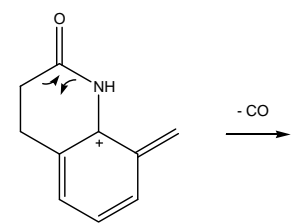

$\mathrm{m} / 2160$ (Ace) (AceD11 m/2167)

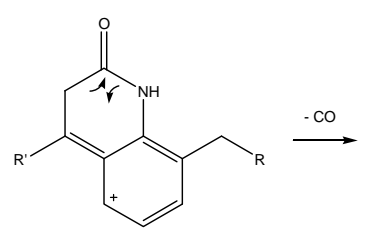

$\mathrm{m} / 2189$ (Ala) (AlaD13 m/2 201)

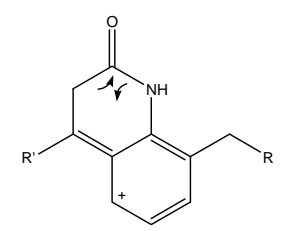

m/z 161 (Ala) (AlaD13 m/z 173)

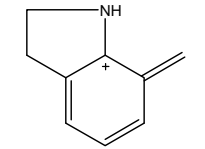

m/2 132 (Ace) (AceD11 m/2139)

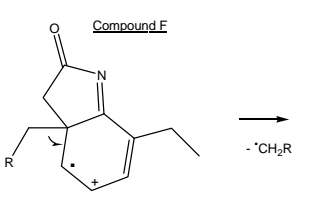

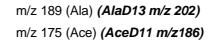

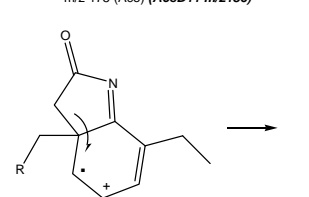

m/2 189 (Ala) (Alab13 m/2 2021

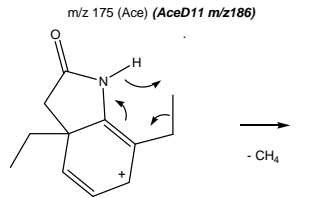

m/2 190 (Ala) (AlaD13 m/2 2033)

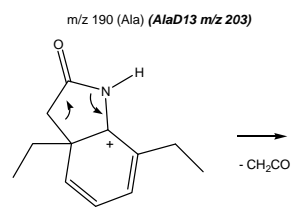

$\mathrm{m} / 2190$ (Ala) (AlaD13 m/2 203)

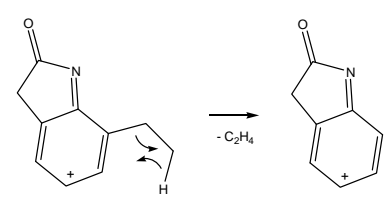

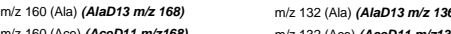
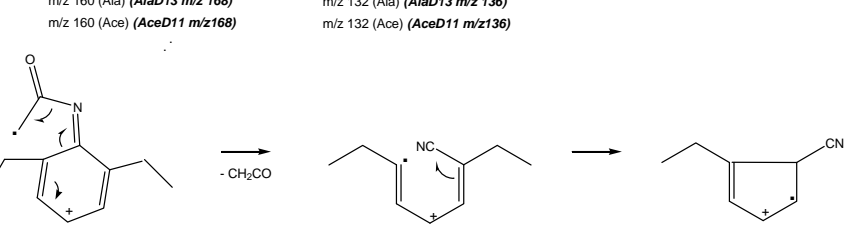

$\mathrm{m} / 2147$ (Ala) (AlaD13 $\mathrm{m} / 2$ 160)

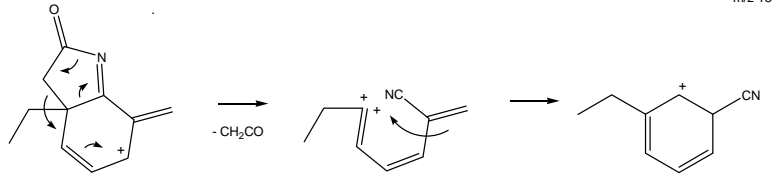

m/2 174 (Ala)(A12013 m/z 184)

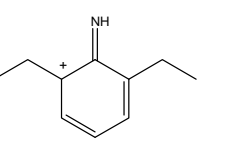

Figure S8: The fragmentation pathway of compounds E(left) and F(right; Ala m/z 189 and Ace m/z175) established on the basis of main MS ${ }^{\mathrm{n}}$ transitions for the degradation products and their analogues from the deuterated pesticides. The $\mathrm{m} / \mathrm{z}$ of the corresponding deuterated analogues used as one of the tools to elucidate the structures is indicated in parenthesis. 
Table S2: GC/MS Molecular weight, retention time, chemical structure and main $\mathrm{MS}^{\mathrm{n}}$ transition obtained by GC-MS in chemical ionization (CI) and electron ionization (EI) for alachlor photoproducts with the shift in masses measured on the deutorated analogue indicated.

\begin{tabular}{|c|c|c|c|c|c|c|c|c|}
\hline & $\begin{array}{l}\text { Molecular } \\
\text { weight }\end{array}$ & $\begin{array}{l}\text { Retention } \\
\text { time } \\
(\mathrm{min}) \\
\end{array}$ & $\begin{array}{l}\text { Shift } \\
\text { Ala-d }_{13}\end{array}$ & $\begin{array}{l}\text { Principale transitions in } \\
\text { CI-MS }^{\mathrm{n}}(\mathrm{m} / \mathrm{z})\end{array}$ & $\begin{array}{c}\text { Principale transitions in } \\
\text { CI-MS }(\mathrm{m} / \mathrm{z}) \\
\text { Ala- } \mathrm{D}_{13} \\
\end{array}$ & $\begin{array}{l}\text { Principale transitions in } \\
\text { EI-MS }^{\mathrm{n}}(\mathrm{m} / \mathrm{z})\end{array}$ & $\begin{array}{c}\text { Principale transitions in EI- } \\
\mathrm{MS}^{\mathrm{n}}(\mathrm{m} / \mathrm{z}) \\
\mathrm{Ala}^{-\mathrm{D}_{13}} \\
\end{array}$ & Structure \\
\hline$\underline{\mathrm{A}}$ & 251 & 27,3 & 13 & $\begin{array}{l}252 \rightarrow 234(-18) \\
252 \rightarrow 220(-32) \\
220 \rightarrow 162(-58) \\
220 \rightarrow 188(-32)\end{array}$ & $\begin{aligned} 265 & \rightarrow 247(-18) \\
265 & \rightarrow 233(-32) \\
233 & \rightarrow 175(-58) \\
233 & \rightarrow 200(-33)\end{aligned}$ & $\begin{array}{l}251 \rightarrow 219(-32) \\
219 \rightarrow 161(-58)\end{array}$ & $\begin{array}{l}264 \rightarrow 232(-32) \\
232 \rightarrow 174(-58)\end{array}$ & \\
\hline$\underline{B}$ & 235 & 24,8 & 13 & $\begin{array}{l}236 \rightarrow 204(-32) \\
204 \rightarrow 162(-42) \\
162 \rightarrow 134(-28)\end{array}$ & $\begin{aligned} & 249 \rightarrow 217(-32) \\
& 217 \rightarrow 175(-42) \\
& 175 \rightarrow 142(-33)\end{aligned}$ & $\begin{array}{l}235 \rightarrow 203(-32) \\
203 \rightarrow 160(-43)\end{array}$ & $\begin{array}{l}248 \rightarrow 215(-33) \\
215 \rightarrow 172(-43)\end{array}$ & \\
\hline$\underline{\mathrm{C}}$ & 191 & 23,5 & 13 & $\begin{aligned} 192 & \rightarrow 150(-42) \\
192 & \rightarrow 164(-28) \\
192 & \rightarrow 174(-18)\end{aligned}$ & $\begin{aligned} 205 & \rightarrow 163(-42) \\
205 & \rightarrow 173(-32) \\
205 & \rightarrow 187(-18)\end{aligned}$ & $\begin{aligned} 191 \rightarrow 176(-15) \\
176 \rightarrow 148(-28) \\
148 \rightarrow 120(-28) \\
191 \rightarrow 162(-29) \\
191 \rightarrow 149(-42) \\
149 \rightarrow 120(-29) \\
149 \rightarrow 134(-15)\end{aligned}$ & $\begin{array}{l}204 \rightarrow 189(-15) \\
189 \rightarrow 161(-28) \\
161 \rightarrow 129(-32) \\
204 \rightarrow 170(-34) \\
204 \rightarrow 162(-42) \\
162 \rightarrow 128(-34) \\
162 \rightarrow 144(-18)\end{array}$ & \\
\hline$\underline{\mathrm{D}}$ & 233 & 25,1 & 12 & $\begin{array}{l}234 \rightarrow 202(-32) \\
202 \rightarrow 160(-42) \\
202 \rightarrow 174(-28) \\
174 \rightarrow 146(-28) \\
160 \rightarrow 132(-28)\end{array}$ & $\begin{array}{l}246 \rightarrow 214(-32) \\
214 \rightarrow 172(-42) \\
214 \rightarrow 186(-28) \\
186 \rightarrow 154(-32) \\
172 \rightarrow 140(-32)\end{array}$ & $\begin{array}{l}233 \rightarrow 202(-31) \\
202 \rightarrow 160(-42)\end{array}$ & $\begin{array}{l}245 \rightarrow 214(-31) \\
214 \rightarrow 172(-42)\end{array}$ & \\
\hline$\underline{E}$ & 189 & 25,9 & 12 & $\begin{aligned} & 190 \rightarrow 174(-16) \\
& 174 \rightarrow 146(-28) \\
& 190 \rightarrow 160(-30) \\
& 160 \rightarrow 132(-28)\end{aligned}$ & $\begin{aligned} 202 & \rightarrow 183(-19) \\
183 & \rightarrow 155(-28) \\
202 & \rightarrow 167(-35) \\
167 & \rightarrow 139(-28)\end{aligned}$ & $\begin{aligned} 189 & \rightarrow 160(-29) \\
189 & \rightarrow 174(-15) \\
174 & \rightarrow 146(-28) \\
189 & \rightarrow 161(-28)\end{aligned}$ & $\begin{aligned} & 201 \rightarrow 167(-34) \\
& 201 \rightarrow 183(-18) \\
& 183 \rightarrow 155(-28) \\
& 201 \rightarrow 173(-28)\end{aligned}$ & \\
\hline$\underline{F}$ & 189 & 24,3 & 13 & $\begin{array}{l}190 \rightarrow 174(-16) \\
174 \rightarrow 132(-42) \\
190 \rightarrow 148(-42)\end{array}$ & $\begin{aligned} & 203 \rightarrow 184(-19) \\
& 184 \rightarrow 142(-42) \\
& 203 \rightarrow 161(-42)\end{aligned}$ & $\begin{array}{l}189 \rightarrow 160(-29) \\
160 \rightarrow 132(-28) \\
189 \rightarrow 147(-42)\end{array}$ & $\begin{aligned} 202 & \rightarrow 168(-34) \\
168 & \rightarrow 136(-32) \\
202 & \rightarrow 160(-42)\end{aligned}$ & \\
\hline
\end{tabular}


Table S3: Molecular weight, retention time, chemical structure and main daughter ions for the degradation product for alachlor in LC-MS.

\begin{tabular}{|c|c|c|c|c|c|c|c|c|c|}
\hline Compound & $\begin{array}{l}\text { Retention } \\
\text { Time (min) }\end{array}$ & $\begin{array}{l}\mathrm{MH}^{+} \\
\mathrm{m} / \mathrm{z}\end{array}$ & $\begin{array}{l}\text { Shift in u.m.a } \\
\text { (Ala-D13) }\end{array}$ & $\begin{array}{l}\text { Experimental } \\
\text { mass }\end{array}$ & $\begin{array}{c}\text { Theoretical } \\
\text { mass }\end{array}$ & $\begin{array}{l}\text { Molecular } \\
\text { formula }\end{array}$ & Error (mDa) & Error (PPM) & $\begin{array}{c}\text { Main } \\
\text { daughter ions } \\
\text { (CID) }\end{array}$ \\
\hline A & 3,4 & 252 & +13 & 252.1571 & 252.1600 & $\mathrm{C}_{14} \mathrm{H}_{22} \mathrm{NO}_{3}$ & $-2,9$ & $-11,5$ & $\begin{array}{c}252-220-222- \\
190-162\end{array}$ \\
\hline B & 4,8 & 236 & +13 & 236.1638 & 236.1651 & $\mathrm{C}_{14} \mathrm{H}_{22} \mathrm{NO}_{2}$ & $-1,3$ & $-5,5$ & 236-204-162 \\
\hline D & 2,9 & 234 & +12 & 234.1488 & 234.1494 & $\mathrm{C}_{14} \mathrm{H}_{20} \mathrm{NO}_{2}$ & $-0,6$ & $-2,6$ & $234-202-174$ \\
\hline
\end{tabular}




\section{References}

Battaglinand JFaW. Potential toxicity of pesticides measured in midwestern streams to aquatic organisms. Water Science \& Technology 2002; 45: 95-103.

Belden Jason B GRJ, Martin Jeffrey D, and Lydy Michael J. Relative Toxicity and Occurrence Patterns of Pesticide Mixtures in Streams Draining Agricultural Watersheds Dominated by Corn and Soybean Production. Integrated Environmental Assessment and Management 2007; 3: 90-100.

Bonnet JL, Bonnemoy F, Dusser M, Bohatier J. Assessment of the potential toxicity of herbicides and their degradation products to nontarget cells using two microorganisms, the bacteria Vibrio fischeri and the ciliate Tetrahymena pyriformis. Environmental Toxicology 2007; 22: 78-91.

Christensen ER, Kusk KO, Nyholm N. Dose-response regressions for algal growth and similar continuous endpoints: Calculation of effective concentrations. Environmental Toxicology and Chemistry 2009; 28: 826-835.

Coffinet S, Rifai A, Genty C, Souissi Y, Bourcier S, Sablier M, et al. Characterization of the photodegradation products of metolachlor: structural elucidation, potential toxicity and persistence. Journal of Mass Spectrometry 2012; 47: 1582-1593.

EFSA EFSA. Conclusion regarding the peer review of the pesticide risk assessment of the active substance acetochlor, EFSA scientific report 153. EFSA, Parma. 2008.

Fairchild JF, Ruessler DS, Carlson AR. Comparative sensitivity of five species of macrophytes and six species of algae to atrazine, metribuzin, alachlor, and metolachlor. Environmental Toxicology and Chemistry 1998; 17: 1830-1834.

Fairchild JF, Ruessler DS, Haverland PS, Carlson AR. Comparative Sensitivity of \&lt;i\&gt;Selenastrum capricornutum\&lt;/i\&gt; and \&lt;i\&gt;Lemna minor\&lt;/i\&gt; to Sixteen Herbicides. Archives of Environmental Contamination and Toxicology 1997; 32: 353-357.

ISO6341. Water quality -- Determination of the inhibition of the mobility of Daphnia magna Straus (Cladocera, Crustacea) -- Acute toxicity test. International Organization for Standardization, Switzerland 1996.

ISO8692. Water quality -- Freshwater algal growth inhibition test with unicellular green algae. International Organisation for Standardisation, Switzerland 2004.

ISO11348-3. Water quality -- Determination of the inhibitory effect of water samples on the light emission of Vibrio fischeri (Luminescent bacteria test) -- Part 3: Method using freeze-dried bacteria. International Organization for Standardization, Switzerland 1998.

Köck M, Farré M, Martínez E, Gajda-Schrantz K, Ginebreda A, Navarro A, et al. Integrated ecotoxicological and chemical approach for the assessment of pesticide pollution in the Ebro River delta (Spain). Journal of Hydrology 2010; 383: 73-82.

Lapertot M, Ebrahimi S, Oller I, Maldonado MI, Gernjak W, Malato S, et al. Evaluating Microtox@ as a tool for biodegradability assessment of partially treated solutions of pesticides using $\mathrm{Fe} 3+$ and $\mathrm{TiO} 2$ solar photo-assisted processes. Ecotoxicology and Environmental Safety 2008; 69: 546-555.

Malato S. Evaluation and optimization of WW treatment by AOPs. Case study I: pesticide degradation INNOVAMED Plataforma Solar de Almería-CIEMAT. Carretera Senés km4, Tabernas (Almería). 04200-Spain. 2007. 

chloroacetamide herbicides from UV-treatment of water

Yasmine Souissi ${ }^{a}$, Stéphane Bouchonnet ${ }^{a}$, Sophie Bourcier ${ }^{a}$, Kresten Ole Kusk ${ }^{b}$, Michel Sablier $^{a}$, Henrik Rasmus Andersen ${ }^{b}$

a Ecole Polytechnique, Laboratoire des Mécanismes Réactionnels, CNRS, route de Saclay, 91128 Palaiseau cedex, France.

${ }^{\mathbf{b}}$ Department of Environmental Engineering, Technical University of Denmark, Miljoevej 113, 2800 Kgs. Lyngby, Denmark. 


\section{Detailed experimental sections}

1- Chemical analysis conditions

1-1- GC-MS experimental condition

1-2- LC-MS experimental condition

2- Ecotoxicity bioassays conditions

1.1. Daphnia magna acute immobilization tests

1.2. Pseudokirchneriella subcapitata growth inhibition test

1.3. Bioluminescence inhibition test of Vibrio fischeri

\section{Supplementary tables and figures}

List of tables:

Table S1 Literature survey of $50 \%$ effective concentrations $\left(\mathrm{EC}_{50} \mathrm{~s}\right)$ of the investigated herbicides with the three used ecotoxicity tests

List of figures:

Figure S1 Concentration-response curves obtained for the three herbicides and their photodegradates with Daphnia magna toxicity test.

Figure S2 Concentration-response curves obtained for the three herbicides and their photodegradates with Pseudokirchneriella subcapitata growth inhibition test

Figure S3 Concentration-response curves obtained for metolachlor and alachlor solutions and their photodegradates with Vibrio fischeri bioluminescence inhibition test 


\section{Chemical analysis conditions}

\section{1-1- GC-MS experimental conditions:}

All experiments were carried out by automatically injecting $1.0 \mu \mathrm{L}$ of sample in the splitless mode at a rate of $50 \mu \mathrm{L} \cdot \mathrm{s}^{-1}$. Helium gas was used as a carrier at a flow rate of $1.4 \mathrm{~mL} \cdot \mathrm{min}^{-1}$. The oven temperature started at $50{ }^{\circ} \mathrm{C}$, was held for $0.5 \mathrm{~min}$, then increased incrementally $10{ }^{\circ} \mathrm{C} \cdot \mathrm{min}^{-}$

${ }^{1}$ up to $320^{\circ} \mathrm{C}$ where it was held for $7.5 \mathrm{~min}$. The total duration of GC analysis was $35 \mathrm{~min}$. The manifold, ion trap electrodes and transfer line temperatures were set at $120{ }^{\circ} \mathrm{C}, 220^{\circ} \mathrm{C}$ and 300 ${ }^{\circ} \mathrm{C}$, respectively. Calibration of the mass spectrometer was automatically performed using ions resulting from electron ionization (EI) of perfluorotributylamine. Chemical ionization (CI) experiments were carried out using methanol as the reagent gas. Spectra were recorded using the automatic gain control (AGC) function with a target value of 20.000 in EI, 5000 in CI. In all experiments emission current was set to $10 \mu \mathrm{A}$ and the electron multiplier voltage to $1850 \mathrm{~V}$. Full scan mass spectra were recorded on a scanning range from $\mathrm{m} / \mathrm{z} 50$ to $\mathrm{m} / \mathrm{z} 450$. An isolation window of one mass unit was employed for multiple stage mass spectrometry $\left(\mathrm{MS}^{\mathrm{n}}\right)$ experiments. In $\mathrm{MS}^{\mathrm{n}}$, precursor ions were stored with a $\mathrm{q}_{\mathrm{z}}$ stability parameter of 0.30 , and fragmented by collision induced dissociation with different activation energy values ranging from 0.2 to $1.0 \mathrm{~V}$ using the resonant excitation mode.

\section{1-2- LC-MS experimental conditions:}

The $\mathrm{CH}_{3} \mathrm{CN}+$ formic acid $(0.1 \%)(\mathrm{A}) / \mathrm{H}_{2} \mathrm{O}+$ formic acid $(0.1 \%)(\mathrm{B})$ gradient used was the following: $40 \% \mathrm{~A} / \mathrm{60 \%} \mathrm{B}$ from 0 to $11.0 \mathrm{~min}, 100 \% \mathrm{~A}$ from 11.1 to $20.0 \mathrm{~min}$ and $40 \% \mathrm{~A} / 60 \%$ B from $20.1 \mathrm{~min}$ to $30.0 \mathrm{~min}$. A constant flow of $0.2 \mathrm{~mL} \cdot \mathrm{min}^{-1}$ was used. The volume of injected samples was $2 \mu \mathrm{L}$. The electrospray interface was operated under the following conditions: capillary voltage $2.6 \mathrm{kV}$, cone voltage $20 \mathrm{~V}$, source temperature $100^{\circ} \mathrm{C}$, desolvation temperature $450^{\circ} \mathrm{C}$, and collision energy 5 and $15 \mathrm{eV}$. Accurate mass measurements (four decimal places) were carried out at a resolution higher than 5000 (full width at half maximum) using an independent reference spray (phosphoric acid) via the LockSpray interference to ensure accuracy. The accurate mass and the elemental composition for all ions are obtained using

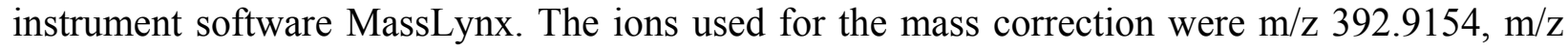
294.9385 and $\mathrm{m} / \mathrm{z} 196.9616$. 


\section{2-1- Daphnia magna acute immobilization tests}

This aquatic animal is extensively used as a test organism in aquatic toxicology due to their small size, short life cycle and amenability to lab culture. Static acute 24-48 h assays were conducted according to internationally accepted Standard Methods (ISO6341, 1996). A healthy culture of Daphnia magna is used as the source of mother organism. The day before the start of the test, the mother cultures were cleaned up and all animals except the mother animals were removed. Thus, the neonates that were born in the night and were less than $24 \mathrm{~h}$ were used for the test. Immobility at $24 \mathrm{~h}$ and $48 \mathrm{~h}$ is the bioassay endpoint, assumed to be equivalent to mortality. In each test a control and 5 (or 6) test concentrations were included in each sample. Each concentration was tested using four replicate vessels with 5 neonates per replicate. Daphnia neonates exposed to the control and different concentrations were incubated in darkness at $20^{\circ} \mathrm{C}$. After $24 \mathrm{~h}$ and $48 \mathrm{~h}$ of exposure the number of immobilized organisms were determined. The EC50 is determined as the concentrations producing 50\% of immobilization as described below.

\section{2-2- Pseudokirchneriella subcapitata growth inhibition test}

A growth inhibition test using the green algae Pseudokirchneriella subcapitata was performed according to ISO 8692 (ISO8692, 2004). A series of dilutions of parent compound and photolyzed solution samples were prepared. 10-ml algal cultures in 20-ml growth vials capped with lids were used with a small hole drilled to allow equilibration with atmospheric $\mathrm{CO}_{2}$ while minimizing any volatilization losses from solution. The sample dilutions and the controls were inoculated with the microalgae from the concentrated suspension to obtain $5-10 \cdot 10^{3}$ cells $/ \mathrm{mL}$ as the start algae density. Tests were conducted in triplicate with six control replicates and a $\mathrm{pH}$ of approximately 7.8. The samples were incubated for $72 \mathrm{~h}$ at $20^{\circ} \mathrm{C}$, with a continuous illumination of 10,000 lux from fluorescent tubes. The algal biomass was measured by fluorescence on acetone extracts of samples taken immediately after addition of the algae $(0 \mathrm{~h})$, after 24,48 and $72 \mathrm{~h}$ of exposure with a Hitachi F-2000 Fluorescence Spectrophotometer (Hitachi, Japan) with excitation light at $430 \mathrm{~nm}$ and emission light at $671 \mathrm{~nm}$. Samples from the vials were extracted with acetone $24 \mathrm{~h}$ prior to the fluorescence measurements. The fluorescence was used directly for calculation of growth rates in each vial. 
The experimental procedure for conducting the bacterial bioluminescence assay is based on the ISO protocol (ISO11348-3, 1998). The analysis was carried out with all dilution and reagents maintained at $15^{\circ} \mathrm{C}$. A working solution of luminescent bacteria was prepared by reconstituting a vial of frozen lyophilized Vibrio fishier cells using $12.5 \mathrm{ml}$ of the reagent diluent provided by the manufacturer. The reconstituted solution was equilibrated for a minimum of 30 minutes at $4^{\circ} \mathrm{C}$. The hydrated cell suspension is usable for several hours when kept chilled. The osmolality is adjusted in order to obtain $2 \% \mathrm{w} / \mathrm{v} \mathrm{NaCl}$ in each solution or sample. Bacterial reagents are reconstituted just prior to the analysis and the pre-incubation times follow standard protocols. In all measures, the percent of inhibition (\% I) was determined by comparing the relative response of the control to that of the diluted sample. Each dilution was tested in duplicate and performed at $15^{\circ} \mathrm{C}$.

A dilution series of the samples to be analysed were prepared in sodium chloride solution (2\% $\mathrm{NaCl}$ ). Different concentration intervals were used for the tested chemicals depending on the expected EC50. For the photolyzed solutions, a larger concentration range was adopted as the EC50 values were unknown. The sample $\mathrm{pH}$ values were approximately 7. A fixed amount of bacteria (100 $\mu \mathrm{l}$ of the reconstituted cell suspension) was added to the dilution vials. Luminescence was measured at time zero (before addition of test solution) and then after 5, 15 and $30 \mathrm{~min}$ and compared to the measured value of a bacterial control. The concentration of toxicants in the test which causes a $50 \%$ inhibition of bioluminescence after exposure for 5,15 or 30 min was designated as the EC50 value. The measurements of bioluminescence were made using the luminometer Luminoskan TL Plus (Thermo lab system).

\section{2-4- Statistical analysis}

Due to the different nature of the endpoints (continued responses in algal and biotox tests and quantal responses in the Daphnia test), the ecotoxicity test results were treated with different statistical methods.

Specific algal growth rates were calculated from the exponential increase in cell density in each replicate using the standard formula shown in ISO 8692 (ISO8692, 2004) assuming exponential growth during the 72-h duration of the assays. The inhibition of growth rates are calculated as percentages of the mean growth rate of the controls and plotted against the logarithm of the concentration. Further data treatment and calculation of log-norm and Weibull concentration- 
response curves and estimation of EC50 and EC10 with 95\% confidence intervals were carried 131 out on a Windows-based computer program (Christensen et al., 2009).

132 The relative inhibition of Vibrio fischeri bioassays were determined using equations (1) and (2) 133 corresponding respectively to the correction factor for each measuring time (KF5, KF15 and $134 \mathrm{KF} 30$ ) and the relative response (REL\% xmin). The dose-response curves exhibiting the 135 bioluminescence inhibition were generated by the same statistical program as the algae growth 136 inhibition. Further treatment of data was performed with the program previously mentioned 137 (Christensen et al., 2009).

$$
\mathrm{KF}_{\mathrm{x}}=\mathrm{IC}_{\mathrm{x}} / \mathrm{IC}_{0}
$$
where $\mathrm{ICx}=$ Average luminescence of control samples after contact time (x min)

$$
\mathrm{REL} \% \mathrm{xmin}=\left[\mathrm{IT}_{\mathrm{x}} / \mathrm{KF}_{\mathrm{x}} \times \mathrm{IT}_{0}\right] \times 100
$$

141 where ITx $=$ Luminescence intensity of test sample after contact time Daphnia magna toxicity 142 assay results were analyzed statistically with a probit procedure using Toxcalc ${ }^{\circ}$ (version 5.0, 143 ToxCalc. 2001. Tidepool Scientific, LLC. McKinleyville, CA, USA). Median effective 144 concentrations and 95\% fiducial limits as well as probit values were calculated. 


\section{Tables and Figures}

148

Table S1 Literature survey of fifty percent effective concentration $\mathrm{EC}_{50} \mathrm{~S}$ of the investigated herbicides with the three used ecotoxicity tests

\begin{tabular}{|c|c|c|c|c|c|c|}
\hline & \multicolumn{2}{|c|}{ Alachlor } & \multicolumn{2}{|c|}{ Acetochlor } & \multicolumn{2}{|c|}{ Metolachlor } \\
\hline Bioassay & EC 50 & Reference & EC 50 & Reference & EC 50 & Reference \\
\hline \multirow{5}{*}{$\begin{array}{c}\text { Pseudokirchneriella } \\
\text { subcapitata } \\
\mathrm{EC}_{50} \mu \mathrm{g} / \mathrm{L}\end{array}$} & 10 & Köck et al., 2010 & 0.52 & EFSA, 2008 & 55 & $\begin{array}{c}\text { Köck et al., } \\
2010\end{array}$ \\
\hline & $64-9$ & Fairchild et al., 1997 & 1.4 & $\begin{array}{c}\text { Belden Jason B } \\
2007\end{array}$ & 57 & $\begin{array}{l}\text { Battaglinand } \\
\quad, 2002\end{array}$ \\
\hline & 5.9 & Battaglinand 2002 & 1.43 & Battaglinand, 2002 & $8472-95$ & $\begin{array}{l}\text { Fairchild et } \\
\text { al., } 1998\end{array}$ \\
\hline & 10 & $\begin{array}{l}\text { Fairchild et al., } \\
1998\end{array}$ & 2.50 & Own results & 44.3 & Own results \\
\hline & 6.69 & Own results & & & & \\
\hline \multirow{4}{*}{$\begin{array}{l}\text { Daphnia magna } \\
\qquad \mathrm{EC}_{50} \mathrm{mg} / \mathrm{L}\end{array}$} & 10 & Köck et al., 2010 & 7.4 & EFSA, 2008 & 23.5 & $\begin{array}{c}\text { Köck et al., } \\
2010\end{array}$ \\
\hline & & & 8.2 & Belden Jason B & & \\
\hline & 7.50 & Own results & & 2007 & 22.3 & Own results \\
\hline & & & 6.29 & Own results & & \\
\hline \multirow{4}{*}{$\begin{array}{c}\text { Vibrio Fischeri } \\
\text { EC }_{50} 15 \mathrm{~min} \mathrm{mg} / \mathrm{L}\end{array}$} & 160 & Köck et al., 2010 & & \multirow{4}{*}{ NA* } & & \\
\hline & $206 \pm 39$ & Bonnet et al., 2007 & & & 17 & Köck et al.., \\
\hline & 105.4 & Lapertot et al.., 2008 & & & 171 & 2010 \\
\hline & 155 & Own results & & & 17.1 & \\
\hline
\end{tabular}

$149 \quad *$ NA: Not Available 

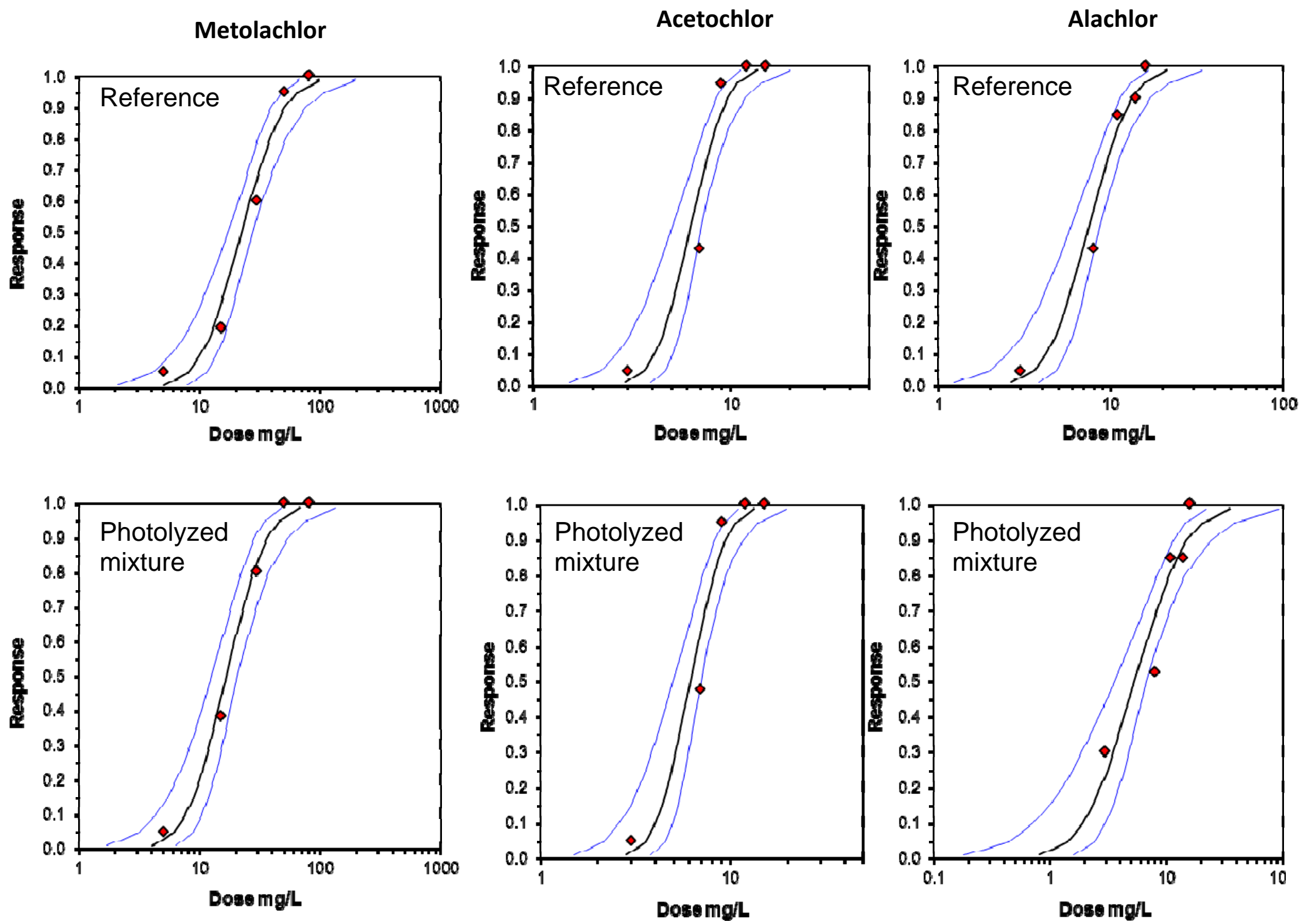
indicate the upper and lower $95 \%$ Fiducial limits, line in black represents the optimal fit. 
153

Effect curve fit : Metolchlor Reference Solution

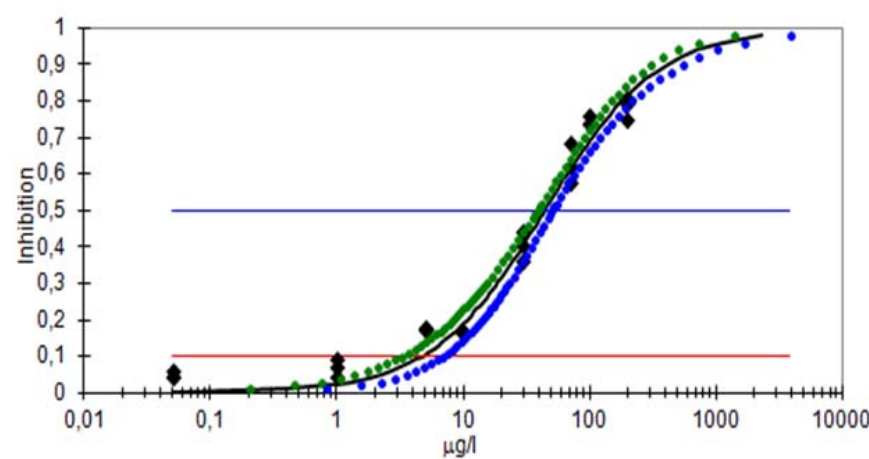

Effect curve fit : Metolchlor Photolyzed Solution

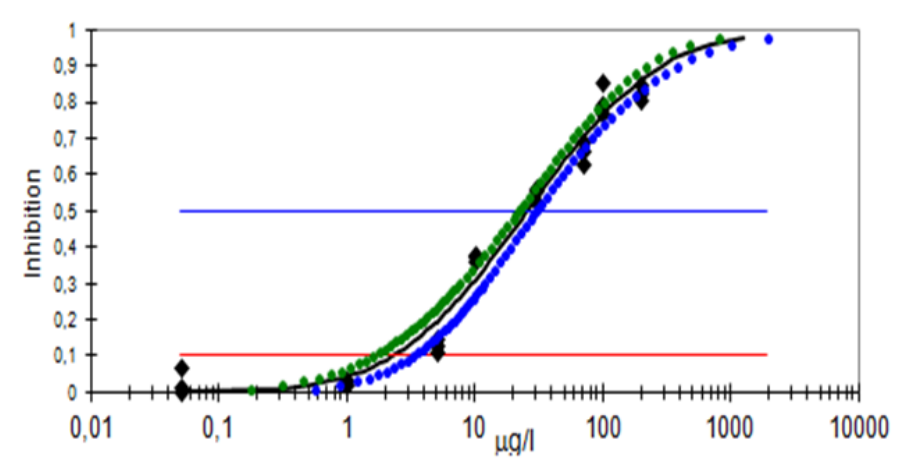

Effect curve fit : Acetochlor Reference Solution

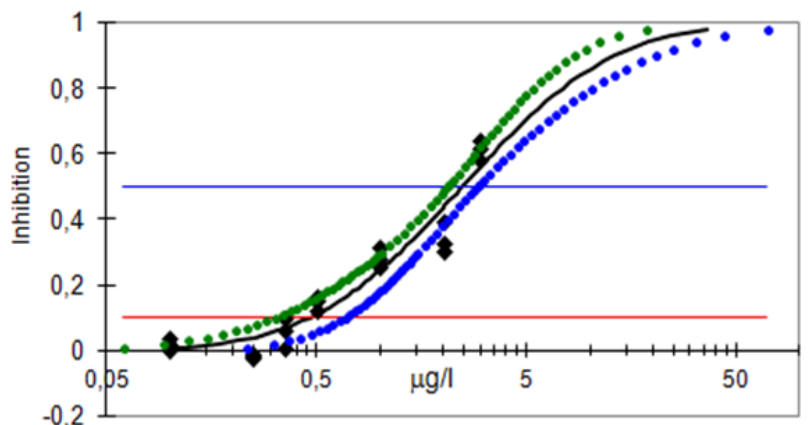

Effect curve fit : Acetochlor Photolyzed Solution

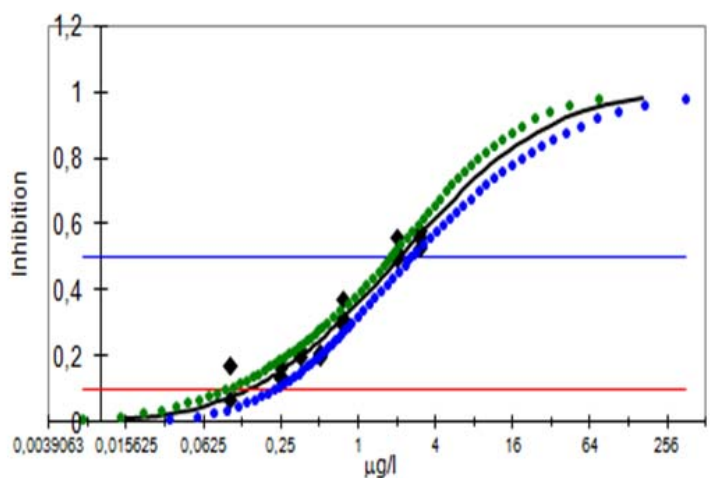

Effect curve fit : Alachlor Reference solution

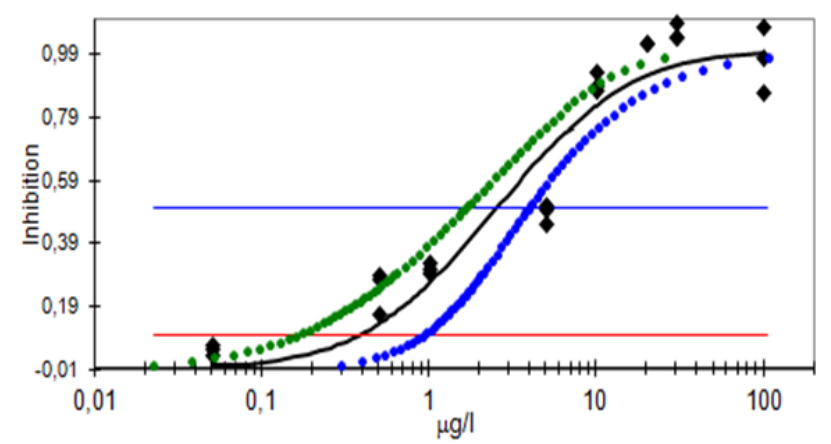

Effect curve fit : Alachlor Photolyzed solution

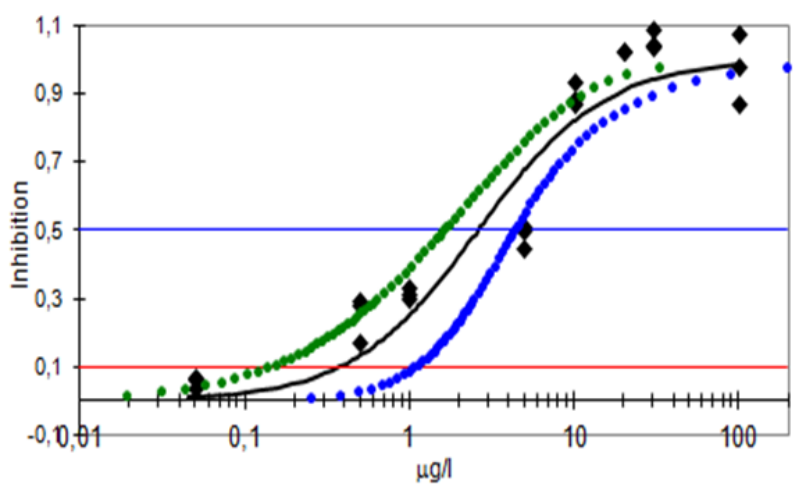

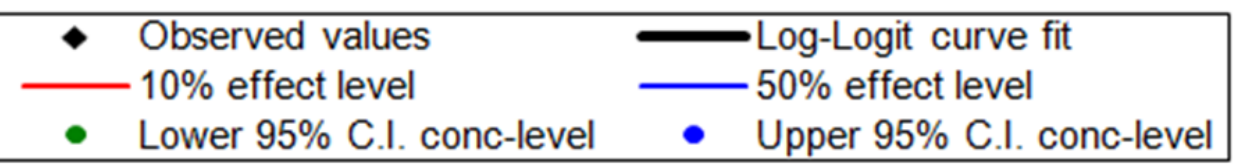

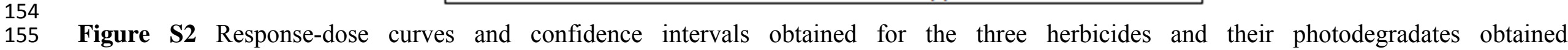
withPseudokirchneriella subcapitata growth inhibition test. 
Effect curve fit : Metolchlor Reference Solution

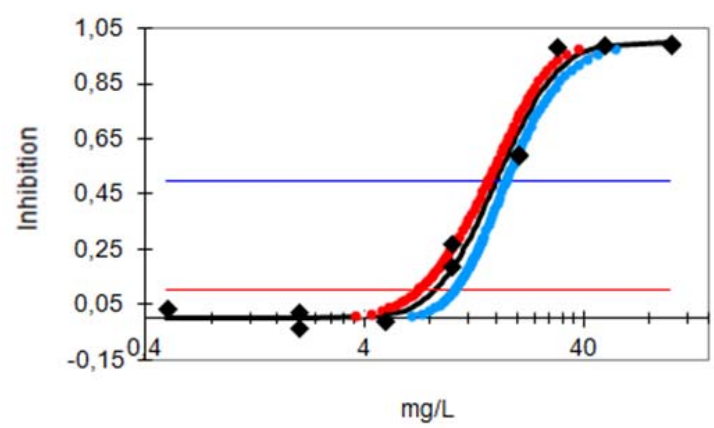

Effect curve fit : Metolchlor Photolyzed Solution

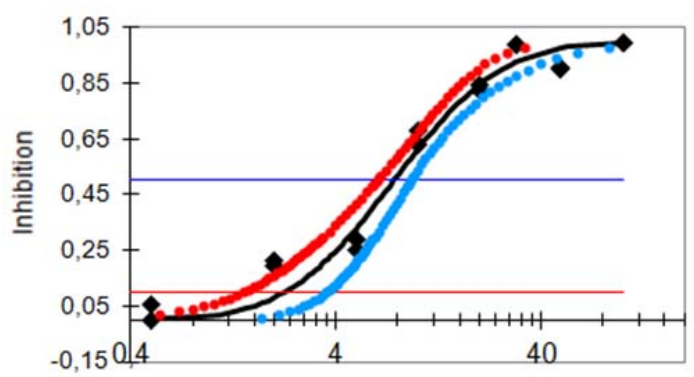

$\mathrm{mg} / \mathrm{L}$
Effect curve fit : Alachlor Reference solution

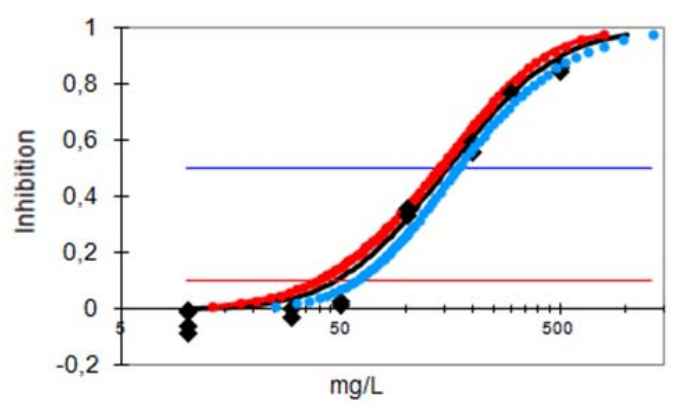

Effect curve fit : Alachlor Photolyzed solution

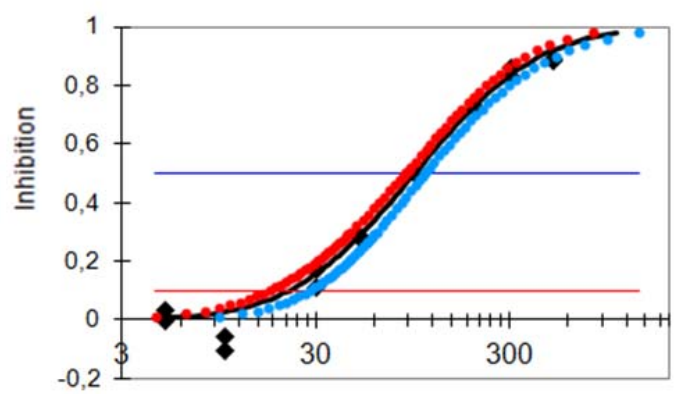

$\mathrm{mg} / \mathrm{L}$

Figure S3 Response-dose curves and confidence intervals for reference and photolyzed metolachlor and alachlor solutions with Vibrio fischeri bioluminescence inhibition test. 


\section{References}

Battaglinand JFaW. Potential toxicity of pesticides measured in midwestern streams to aquatic organisms. Water Science \& Technology 2002; 45: 95-103.

Belden Jason B GRJ, Martin Jeffrey D, and Lydy Michael J. Relative Toxicity and Occurrence Patterns of Pesticide Mixtures in Streams Draining Agricultural Watersheds Dominated by Corn and Soybean Production. Integrated Environmental Assessment and Management 2007; 3: 90100.

Bonnet JL, Bonnemoy F, Dusser M, Bohatier J. Assessment of the potential toxicity of herbicides and their degradation products to nontarget cells using two microorganisms, the bacteria Vibrio fischeri and the ciliate Tetrahymena pyriformis. Environmental Toxicology 2007; 22: 78-91.

Christensen ER, Kusk KO, Nyholm N. Dose-response regressions for algal growth and similar continuous endpoints: Calculation of effective concentrations. Environmental Toxicology and Chemistry 2009; 28: 826-835.

EFSA EFSA. Conclusion regarding the peer review of the pesticide risk assessment of the active substance acetochlor, EFSA scientific report 153. EFSA, Parma. 2008.

Fairchild JF, Ruessler DS, Carlson AR. Comparative sensitivity of five species of macrophytes and six species of algae to atrazine, metribuzin, alachlor, and metolachlor. Environmental Toxicology and Chemistry 1998; 17: 1830-1834.

Fairchild JF, Ruessler DS, Haverland PS, Carlson AR. Comparative Sensitivity of \&lt;i\&gt;Selenastrum capricornutum\&lt;/i\&gt; and \&lt;i\&gt;Lemna minor\&lt;/i\&gt; to Sixteen Herbicides. Archives of Environmental Contamination and Toxicology 1997; 32: 353-357.

ISO6341. Water quality -- Determination of the inhibition of the mobility of Daphnia magna Straus (Cladocera, Crustacea) -- Acute toxicity test. International Organization for Standardization, Switzerland 1996.

ISO8692. Water quality -- Freshwater algal growth inhibition test with unicellular green algae. International Organisation for Standardisation, Switzerland 2004.

ISO11348-3. Water quality -- Determination of the inhibitory effect of water samples on the light emission of Vibrio fischeri (Luminescent bacteria test) -- Part 3: Method using freeze-dried bacteria. International Organization for Standardization, Switzerland 1998.

Köck M, Farré M, Martínez E, Gajda-Schrantz K, Ginebreda A, Navarro A, et al. Integrated ecotoxicological and chemical approach for the assessment of pesticide pollution in the Ebro River delta (Spain). Journal of Hydrology 2010; 383: 73-82.

Lapertot M, Ebrahimi S, Oller I, Maldonado MI, Gernjak W, Malato S, et al. Evaluating Microtox@ as a tool for biodegradability assessment of partially treated solutions of pesticides using Fe3+ and $\mathrm{TiO} 2$ solar photo-assisted processes. Ecotoxicology and Environmental Safety 2008; 69: 546-555.

Malato S. Evaluation and optimization of WW treatment by AOPs. Case study I: pesticide degradation INNOVAMED Plataforma Solar de Almería-CIEMAT. Carretera Senés km4, Tabernas (Almería). 04200-Spain. 2007. 